\title{
Effect of Nutritional Factors and Copper on the Regulation of Laccase Enzymes Production in Pleurotus ostreatus
}

\author{
Dinary Durán-Sequeda1, 2 *, Daniela Suspes ${ }^{1}$, Estibenson Maestre, Manuel Alfaro², Gúmer Perez², Lucía Ramírez², \\ Antonio G. Pisabrarro ${ }^{2, *}$, and Rocío Sierra ${ }^{1}$
}

\author{
1 Product and Process Design Group (GDPP), Department of Chemical and Food Engineering, Univer- \\ sidad de los Andes, Colombia \\ d.suspes2053@uniandes.edu.co (D.S); stibensonmac@gmail.com (E.M); rsierra@uniandes.edu.co \\ ${ }^{2}$ Institute for Multidisciplinary Research in Applied Biology ( IMAB), Public University of Navarre \\ (UPNA), 31006 Pamplona, Navarre, Spain \\ manuel.alfaro@unavarra.es (M.A); gumer.perez@unavarra.es (G.P.); lramirez@unavarra.es (L.R); \\ gpisabarro@unavarra.es (A.G.P.) \\ *Correspondence: de.duran@uniandes.edu.co, gpisabarro@unavarra.es
}

\begin{abstract}
This research aimed to establish the relationship between carbon-nitrogen nutritional factors and copper sulfate on laccase activity (LA) by Pleurotus ostreatus. Culture media composition was tested to choose the nitrogen source. Yeast extract (YE) was selected as a better nitrogen source than ammonium sulfate. Then, the effect of glucose and YE concentrations on biomass production and LA as response variables was evaluated using central composite experimental designs with and without copper. The results showed that the best culture medium composition was glucose $45 \mathrm{gL}^{-1}$ and YE $15 \mathrm{gL}^{-1}$, simultaneously optimizing these two response variables. The fungal transcriptome was obtained in this medium with or without copper, and the differentially expressed genes were found. Main up-regulated transcripts included three laccase genes (lacc2, lacc6, and lacc10) regulated by copper, whereas the principal down-regulated transcripts included a copper transporter (ctr1) and a regulator of nitrogen metabolism (nmr1). These results suggest that Ctr1, which facilitates the entry of copper in the cell, is regulated by nutrient-sufficiency conditions. Once inside, copper induces transcription of laccase genes. This finding could explain why a 10 to 20 -fold increase in LA occurs with copper compared to cultures without copper when using the optimal concentration of YE as nitrogen sources.
\end{abstract}

Keywords: Multi-copper oxidase; copper-transporter; nutrient-sufficient conditions, white-rot fungus

\section{Introduction}

Fungal laccases are glycosylated, multi-copper oxidases that catalyze the oxidation of hydroxyl functional groups on various substrates and the molecular oxygen reduction to water [1-3]. As laccases can oxidize phenolic and non-phenolic compounds, these enzymes are attractive in many processes or biotechnological applications, such as bioremediation, wastewater treatment, nanobiotechnology, biofuel production, pharmaceutical, and food industry $[4,5]$.

Pleurotus ostreatus is a white-rot fungus considered a biotechnological model for studying and producing fungal laccases [6]. This fungus is easily cultivable on several synthetic or natural media [7], its genome has been decoded [8], and it contains a laccase multi-gene family [9]. Despite these advantages, laccase production in the P. ostreatus cultures is affected by complex and not fully understood gene expression regulatory mechanisms at multiple levels.

At the genome level, 12 laccase genes have been identified in the genomes of the $P$. ostreatus monokaryotic (mk) strains, mkPC15 and mkPC9 [10]. These genes are distributed 
across several chromosomes of the fungus: seven on chromosome VI (lacc1, lacc4, lacc6, lacc7, lacc9, lacc10, and lacc11), two on chromosome XI (lacc5 and lacc12), and one on chromosomes IV, VII, and VIII (lacc3, lacc8, and lacc2, respectively) [11]. However, each gene's physiological and functional role and the consequences of their clustering are still under study.

At the transcriptional level, each laccase gene expression regulation is mainly controlled by the cis-acting elements localized upstream of the transcriptional start site in the promoter [12]. In addition to the TATA and CAAT putative boxes, other cis-acting elements in these promoter regions differ for each laccase gene on $P$. ostreatus. These additional cis-acting elements can be divided into three groups i) response to nutrient-sufficient conditions (carbon and nitrogen sufficient) including catabolic responsive elements (CRE) and nitrogen binding site (NIT), ii) response to inducers such as metal responsive (MRE), xenobiotic responsive (XRE), and antioxidant responsive elements; and iii) response to stress including heat shock sequence (HSE), and stress-responsive elements (STRE) $[13,14]$. The first and second groups, response to nutritional status and inducers, could be stimulated by changing the culture medium composition; however, these changes have been insufficient to explain the transcriptional profile of laccase in different culture conditions $[15,16]$. Moreover, there is a lack of knowledge about how other transregulatory factors can interact and intervene at this regulation level.

Other laccase regulation mechanisms occurring at the post-transcriptional and posttranslational levels could explain changes in the molecular weight of laccase isoenzymes or the heterogeneity observed in the electrophoretic migration of their isoforms [17]. Most isolated and characterized laccases have an apparent molecular weight ranging from 60 to $85 \mathrm{kDa}$. Although almost all are monomers, Lacc2 can form complex heterodimers $[12,13]$ with a large subunit formed by at least two alternatively spliced variants of the lacc2 gene, and small subunits are produced by translating two different genes $[17,18]$. Concerning the post-translational regulation level, $\mathrm{N}$-glycosylation is the main post-translational modification in fungal laccases [19]. N-glycosylation is critical in several biochemical aspects, such as the folding, location, and catalytic activity of these enzymes [20,21]. On the one hand, N-glycosylation is the main challenge to produce laccases in the heterologous system [22]. On the other hand, these modifications are also affected by the fungal growth conditions and culture medium composition [23].

Since laccase regulation responds to several factors in the composition of the culture medium, a wide range of maximum laccase activities from $P$. ostreatus have been reported for submerged fermentation, as shown in Table 1, where only nutritional factors as carbon, nitrogen source, and laccase inducer are shown (although other culture conditions were also considered in the original studies). The compared media contained different glucose concentrations as the primary carbon source, various organic, inorganic, single, or mixed nitrogen sources, varying concentrations of copper sulfate, a known laccase inducer, and various other inducers derived from lignocellulose. 
Table 1. Carbon, nitrogen, and inducer of laccase source and concentration in culture media with the maximum laccase activity by $P$. ostreatus from literature in SmF.

\begin{tabular}{|c|c|c|c|c|c|c|}
\hline $\begin{array}{c}P . \\
\text { ostreatus } \\
\text { strain }\end{array}$ & $\begin{array}{c}\text { Carbon } \\
\left(\mathrm{gL}^{-1}\right)\end{array}$ & $\begin{array}{l}\text { Nitrogen } \\
\left(g^{-1}\right)\end{array}$ & $\begin{array}{c}\text { Laccse in- } \\
\text { ducer } \\
\left(g^{-1}\right)\end{array}$ & $\begin{array}{c}\text { Max. } \\
\text { Laccase } \\
\text { activity } \\
\text { (UL-1) }\end{array}$ & $\begin{array}{l}\text { Day of } \\
\text { culture }\end{array}$ & Ref. \\
\hline ATCC 32783 & $\begin{array}{l}\text { Glucose } \\
\text { (10) }\end{array}$ & $\begin{array}{c}\text { Yeast extract } \\
\text { (5) }\end{array}$ & $\mathrm{CuSO}_{4}(0.25)$ & $37490 \quad 1$ & 20 & {$[24]$} \\
\hline ATCC 32783 & $\begin{array}{c}\text { Glucose } \\
\text { (10) }\end{array}$ & $\begin{array}{c}\text { Yeast extract } \\
\text { (5) }\end{array}$ & $\mathrm{CuSO}_{4}(0.25)$ & $37000 \quad 1$ & 18 & [25] \\
\hline ATCC 32783 & $\begin{array}{l}\text { Glucose } \\
(10)\end{array}$ & $\begin{array}{c}\text { Yeast extract } \\
\text { (10) }\end{array}$ & $\mathrm{CuSO}_{4}(0.25)$ & $13000 \quad 1$ & 13 & [26] \\
\hline ATCC 32783 & $\begin{array}{l}\text { Glucose } \\
(10.5)\end{array}$ & $\begin{array}{c}\text { Yeast extract } \\
\text { (5) }\end{array}$ & $\mathrm{CuSO}_{4}(0.25)$ & $12000 \quad 1$ & 17 & [27] \\
\hline N001 & $\begin{array}{c}\text { Glucose } \\
\text { (20) }\end{array}$ & $\begin{array}{c}\text { Potato extract } \\
\text { (4) }\end{array}$ & $\begin{array}{l}\mathrm{CuSO}_{4} \\
(0.125)\end{array}$ & $80000^{2}$ & 9 & [28] \\
\hline CP-50 & $\begin{array}{c}\text { Glucose } \\
(20)\end{array}$ & $\begin{array}{c}\text { Yeast extract } \\
(10) \\
\text { Malt extract } \\
(20)\end{array}$ & $\begin{array}{l}\mathrm{CuSO}_{4} \\
(0.125)\end{array}$ & $3780^{2}$ & 3.5 & [29] \\
\hline $\begin{array}{c}\text { ATCC } \\
\text { MYA-2306 }\end{array}$ & $\begin{array}{l}\text { Glucose } \\
\text { (20) }\end{array}$ & $\begin{array}{l}\text { Potato extract } \\
\text { (4) }\end{array}$ & $\begin{array}{c}\mathrm{CuSO}_{4} \\
(0.125) \\
\text { Feluric acid } \\
(0.39)\end{array}$ & $40000 \quad 2$ & 10 & [16] \\
\hline N001 & $\begin{array}{l}\text { Glucose } \\
\text { (10) }\end{array}$ & $\begin{array}{c}\text { Yeast extract } \\
\text { (4) } \\
\text { Malt extract } \\
(10)\end{array}$ & $\begin{array}{c}\mathrm{CuSO}_{4}(0.01) \\
\text { Wheat Straw } \\
\text { Water Ex- } \\
\text { tract }\end{array}$ & $600^{1}$ & 24 & {$[30]$} \\
\hline PO 108 & $\begin{array}{l}\text { Glucose } \\
\text { (10) }\end{array}$ & $\begin{array}{c}\text { Yeast extract } \\
(2) \\
\text { Peptone }(0.42) \\
\text { (NH4)NO3 (2) }\end{array}$ & $\begin{array}{l}\mathrm{CuSO}_{4} \\
(0.005)\end{array}$ & $490^{3}$ & 8 & [31] \\
\hline CP-50 & $\begin{array}{l}\text { Glucose } \\
(10)\end{array}$ & $\begin{array}{c}\text { Yeast extract } \\
(10) \\
\text { Peptone (10) } \\
\text { Tryptone (5) }\end{array}$ & $\begin{array}{l}\text { CuSO4 } \\
\text { Lignin }\end{array}$ & $11000^{2}$ & 4.5 & [32] \\
\hline $\begin{array}{c}\text { (Jacq.:Fr.) } \\
\text { Kumm. } 494\end{array}$ & $\begin{array}{l}\text { Glucose } \\
(10)\end{array}$ & $\begin{array}{c}\text { Yeast extract } \\
(5) \\
\mathrm{NH} 4 \mathrm{Cl}(2)\end{array}$ & $\begin{array}{c}\text { Dry ground } \\
\text { mandarine } \\
\text { peels }(40)\end{array}$ & 501 & 10 & [33] \\
\hline
\end{tabular}

${ }^{1}$ Laccase activity was measured using 2, 6-dimethoxyphenol (DMP) as substrate.

${ }^{2}$ Laccase activity was measured using 2, 2-azinobis-(3-ethylbenzothiazoline-6-sulfonic acid) (ABTS) as substrate.

${ }^{3}$ Laccase activity was measured using syringaldazine as substrate.

$P$. ostreatus, like other fungi, senses carbon and nitrogen sources and their concentrations in the cellular environment through nutrient detection mechanisms and pathways [34]. Usually, these mechanisms distinguish and respond to two nutrient conditions: nutrient-sufficient and nutrient-limited, which are different for each organism [35]. If the fungus assimilates the carbon or the nitrogen sources quickly, and their concentration in the culture medium is high, catabolic repression mechanisms are activated specifically for these nutrient-sufficient conditions. For carbon, the mechanism is called Carbon Catabolite Repression (CCR) [36]. In this case, since glucose is the most assimilated sugar by lignocellulolytic fungi, CCR turns off certain enzymes available only in the absence or scarcity of this sugar [37]. CCR is regulated primarily by the transcription factor Cre [38]. On the other hand, for nitrogen sources, the mechanism is called Nitrogen Metabolite Repression (NMR), and it guarantees the preferential use of ammonium $\left(\mathrm{NH}^{4+}\right)$ or L-glutamine 
as nitrogen sources [39,40]. In filamentous fungi, this mechanism is controlled by the transcription factor Nmr [41]. Both catabolic processes, CCR and NMR, have been described in other fungi, are redundant, and have multiple activations or inhibition checkpoints [4244].

Copper is a metal cofactor in several oxidoreductases involved in cellular redox processes such as respiration, free radical detoxification, pigmentation, collagen maturation, and iron acquisition [45-47]. This metal is present in the environment in two oxidation forms, $\mathrm{Cu}^{+}$and $\mathrm{Cu}^{2+}$ [47], of which the former is recognized as a substrate for the highaffinity copper transporters of the CTR family [47]; hence, environmental $\mathrm{Cu}^{2+}$ should be reduced to $\mathrm{Cu}^{+}$before being up-taken into the cell [48]. In the cell, these copper ionic states can vary in the functional copper-binding sites in proteins classified as type 1 (T1), 2 (T2), or 3 (T3) copper sites [49]. In the T1 copper site, a single copper atom is coordinated by two nitrogen from two His residues, one sulfur from a Cys residue, and typically one sulfur from a Met residue. In the T2 copper site, copper is coordinated by nitrogen ligands typically provided by His and oxygen ligands provided by Asp or Tyr residues; and the last one, the T3 copper site, copper sites are binuclear where two copper atoms are coordinated by three nitrogen from three His residues [49,50]. Fungal multicopper oxidases such as laccases are characterized by the presence of at least one T1 copper site and at least three additional copper atoms (one T2 and two T3) arranged in a trinuclear cluster [51]. In this multicopper catalytic center, the T1 copper is involved in substrate oxidation, while the T2 and T3 coppers catalyze the reduction of molecular oxygen [52]. Therefore, copper has two roles in regulating the laccase activity of $P$. ostreatus: as a catalytic site cofactor and as an inducer of the transcription of some laccase genes.

As systematic research on the interactions between nutritional factors on the laccase activity of $P$. ostreatus is currently scarce, this work aims to consider the interaction between the availability of nutritional factors (carbon and nitrogen) and copper sulfate at $1 \mathrm{mM}$ to determine how the medium composition affects laccase induction by copper. The results to be presented indicate that carbon and nitrogen availability influence the laccase activity only when copper is present in a nutrient-sufficient condition where the transcription of $n m r 1$ and copper transporters are up-regulated.

\section{Materials and Methods}

\subsection{Fungal strain and culture conditions}

The Pleurotus ostreatus strain ANDES-F515, provided by the Laboratory of Mycology and Phytopathology of the Universidad de Los Andes-LAMFU and deposited in the ANDES Natural History Museum (MHN ANDES), was isolated in the Bosque de la Merced, Santa Bárbara village, Bojacá, Cundinamarca, Colombia. The dikaryotic mycelium was maintained and conserved on Malt Extract Agar at $4{ }^{\circ} \mathrm{C}$, with periodic replication of the growth zone for eight days of incubation at $25^{\circ} \mathrm{C}$ in the dark.

The submerged fermentation $(\mathrm{SmF})$ cultures were performed in $250 \mathrm{~mL}$ flasks containing $100 \mathrm{~mL}$ of culture medium. For the experiments made using an inorganic nitrogen source 1.0 or $10.0 \mathrm{gL}^{-1}$ of $\left(\mathrm{NH}_{4}\right)_{2} \mathrm{SO}_{4}$ were added to a minimum salt medium (MSM) composed of $0.5 \mathrm{gL}^{-1} \mathrm{~K}_{2} \mathrm{HPO}_{4}, 0.25 \mathrm{gL}^{-1} \mathrm{MgSO}_{4} \cdot 7 \mathrm{H}_{2} \mathrm{O}, 0.1 \mathrm{gL}^{-1} \mathrm{CaCl}_{2}, 0.5 \mathrm{gL}^{-1} \mathrm{KCl}, 0.5 \mathrm{gL}^{-1}$ thiamine, $2.1 \mathrm{gL}^{-1}$ citric acids, $2.94 \mathrm{gL}^{-1}$ sodium citrate, and 6.5 final $\mathrm{pH}$ adjusted with $0.1 \mathrm{M}$ $\mathrm{NaOH}$. For the experiments made using an organic nitrogen source, yeast extract 5 or 10 $\mathrm{gL}^{-1}$ and glucose were the only medium components. Glucose $\left(0.5,1.0,10\right.$, or $\left.20 \mathrm{gL}^{-1}\right)$ was added to achieve different $\mathrm{C}: \mathrm{N}$ ratios in both experimental conditions.

The elemental compositional analysis of yeast extract (YE) used in this study was performed and revealed a C:N ratio estimated at 4:1.

Only glucose and YE were used in the culture media to evaluate models of surface response optimization using a central composite experimental design. The composition of the media were pairwise combinations of glucose $\left(23.8,30.0,45.0,60.0\right.$, or $\left.66.2 \mathrm{gL}^{-1}\right)$ and YE $\left(4.4,7.5,15.0,22.5\right.$, or $\left.25.6 \mathrm{gL}^{-1}\right)$ according to the results from the experimental design 
shown in section 3.2 (Table 4). All combinations were tested in the absence or presence of $1 \mathrm{mM} \mathrm{CuSO}_{4} \cdot 5 \mathrm{H}_{2} \mathrm{O}\left(0.25 \mathrm{gL}^{-1}\right)$.

All SmF cultures were inoculated with five $4 \mathrm{~mm}$ diameter plugs taken from the growth zone of eight-days Malt Agar plate cultures and incubated at $25^{\circ} \mathrm{C}, 150 \mathrm{rpm}$, in the dark for 21 days. All experiments were performed in duplicate.

\subsection{Biomass production}

Fungal biomass production was gravimetrically determined at 21 days of culture. The culture was filtered through a previously dried and weighed filter paper using a vacuum filter system. The collected, filtered mycelium was dried at $45^{\circ} \mathrm{C}$ for $72 \mathrm{~h}$ and weighed [29].

\subsection{Biochemical analyses}

\subsubsection{Spectrometric analyses}

Laccase activity was determined with ABTS (2,2-azino-bis(3-ethylbenzthiazoline-6sulfonate)) as the substrate [53]. The assay mixture contained $1 \mathrm{mM}$ ABTS, $20 \mathrm{mM}$ sodium acetate buffer ( $\mathrm{pH} 5.0$ ), and $10 \mu \mathrm{L}$ aliquots of an appropriately diluted enzyme sample. Oxidation of ABTS was monitored by following the increase in $A 436\left(\varepsilon 29.3 \mathrm{mM}^{-1} \mathrm{~cm}^{-1}\right)$. A laccase activity unit was defined as the enzyme required to oxidize $1 \mu \mathrm{mol}$ ABTS per minute at $25^{\circ} \mathrm{C}$. Reducing sugars were measured using the 3,5-dinitrosalicylic acid (DNS) reagent by DNS method at $540 \mathrm{~nm}$ [54] using glucose as a reference for the calibration curve. Bradford protein assays (Bio-Rad) were used for total protein quantification. Standards and samples were mixed with Coomassie Blue Assay Reagent G-250 according to the manufacturing instructions. Each reaction was measured at $595 \mathrm{~nm}$ [55].

\subsubsection{Zymogram}

Non-denaturing electrophoresis conditions (native-PAGE) were used to visualize the isoenzymes present in samples [56]. The stacking and running gels contained $4 \%$ and $9 \%$ acrylamide, respectively, and were adjusted to $\mathrm{pH} 6.8$ and 8.8 with Tris- $\mathrm{HCl}$ buffer. The running buffer was Tris-Glycine $\mathrm{pH}$ 8.3. The isozymes were revealed through $30 \mathrm{~min}$ gel staining with ABTS $2 \mathrm{mM}$.

\subsection{RNA isolation and transcriptional analyses}

The fungal biomass produced in the cultures containing $45 \mathrm{gL}^{-1}$ glucose and $15 \mathrm{gL}^{-1}$ $\mathrm{YE}$, with or without $1 \mathrm{mM} \mathrm{CuSO}_{4}$, were harvested on day 12 of culture for RNA isolation. The mycelium was collected by filtration, immediately frozen in liquid nitrogen, and ground to a fine powder in a mortar. Then, $100 \mathrm{ng}$ of the powder were transferred to a 1.5 $\mathrm{mL}$ microcentrifuge tube for total RNA extraction using a Fungal RNA EZNA Kit (Omega Bio-Tek, Norcross, GA, USA) according to the manufacturer guidelines. Finally, the integrity and quantity of RNA were validated using Bioanalyzer (version 2100) and Qubit 2.0 fluorometer.

\subsubsection{Real-time qPCR}

Reverse transcription (RT) was performed using $800 \mathrm{ng}$ per sample of the total RNA to obtain cDNA in a $20 \mu \mathrm{L}$ volume using an iScript cDNA synthesis kit (Bio-Rad, Alcobendas, Spain). The complete reaction mix was incubated according to manufacturing instructions in a thermal cycler (MJ Research, Inc). RT products were diluted 1:20 and kept at $-20{ }^{\circ} \mathrm{C}$ until Real-time qPCRs were performed in a CFX96 real-time system (Bio-Rad Laboratories, SA) using SYBR green dye to detect the product amplification [15]. Each reaction mixture was set to a final volume of $20 \mu \mathrm{L}$ containing $10 \mu \mathrm{L}$ iQ SYBR green supermix (Bio-Rad Laboratories, SA), $2 \mu \mathrm{L}$ of $5 \mu \mathrm{M}$ stock forward and reverse primers (Table 2), $1 \mu \mathrm{L}$ of RT product diluted, and $5 \mu \mathrm{L}$ of sterile water. Cycling conditions were as follows: denaturation $5 \mathrm{~min}$ at $95^{\circ} \mathrm{C}, 40$ cycles for $15 \mathrm{~s}$ at $95^{\circ} \mathrm{C}, 30 \mathrm{~s}$ at $63^{\circ} \mathrm{C}, 15 \mathrm{~s}$ at $72{ }^{\circ} \mathrm{C}$, and a final step using a linear gradient increase of $0.5^{\circ} \mathrm{C}$ every $5 \mathrm{~s}$ from 65 to $95^{\circ} \mathrm{C}$. Each reaction was performed in triplicate, and nontemplate controls (NTCs) were included for 
each primer set. An experimentally validated inter-plate calibrator (IPC) was used to compensate for inter-plate variations. Crossing-point $(\mathrm{Cp})$ values and relative fluorescence units were recorded, and the latter was used to calculate amplification efficiencies by linear regression using the LinReg program [57]. Sar1, gapdh1, actin1, and pep were used as reference genes for normalization (Table 2).

Table 2. Forward $(\mathrm{Fw})$ and reverse (Rv) primers sequence to for the laccase and reference genes [15], [57], [58].

\begin{tabular}{ccc}
\hline Gene name & Primer sequence (Fw) & Primer sequence (Rv) \\
\hline$l a c c 1$ & GGTACATCCTAGCACCCAATG & GACGAGATCAGTTTCCAAGAGG \\
$l a c c 2$ & CCCTGGCAGATTGGTATCATG & ATGACAGCGTAAGGGACAAG \\
$l a c c 3$ & TCGTTTCCGTCTCGTTTCTC & CTGCGAAGATTTGGATGCTGG \\
$l a c c 4$ & CCCCATCCTTTCCATCTTCAC & TAGTTATACACCGAGCTTCCG \\
$l a c c 5$ & CGCATTTGCCGCTTTCTT & GGTGACTAGGACTGAGTATCTC \\
$l a c c 6$ & GTACAACTACGAAAACCCCG & CAAGGTCAAGATGCCAGT \\
$l a c c 7$ & GTTGATAGCCTCCAGATCTTCG & GTAGGATGGCGGAGTTGATG \\
$l a c c 8$ & CATTGGCTGTGACTCGAA & GGATCAGAGAATAGCGTTGG \\
$l a c c 9$ & CTATCCTTCGGTATGCTGGTG & ATATTGATGTCTGCGCCTCC \\
$l a c c 10$ & CCTACTTCCCCTTTGGCTATC & ATGACGAGCAAAGAGTGACC \\
$l a c c 11$ & CCTGAATGGTCTGATCTCTGC & CCTATGACTTGGGCTCTTCG \\
$l a c c 12$ & GTACTCATTTTCGGCTCCTG & CCACGTAGTCCATCGCAATA \\
sar1 & GGATAGTCTTCCTCGTCGATAG & GGGTGCGTCAATCTTGTTAC \\
gapdh1 & TGGTCCATCGCATAAGGA & ACACGGAAGGACAAACCA \\
actin1 1 & AGTCGGTGCCTTGGTTAT & ATACCGACCATCACACCT \\
$P e p$ & GATTCCAGAGGACAAGGACGCAA & AAATCTTCCGCGATACGGGTCACT \\
$l a c c 1$ & GGTACATCCTAGCACCCAATG & GACGAGATCAGTTTCCAAGAGG \\
\hline
\end{tabular}

\subsection{2. mRNA-seq analysis}

Illumina compatible libraries were prepared to be sequenced using the Illumina Nova Seq 6000 system from an mRNA isolate originating from RNA total. Following sequencing, RNA-seq data were filtered for assurance quality using FastQC and trimmed with BBDuk to remove adapters and low-quality reads (https://jgi.doe.gov/data-andtools/bbtools/bb-tools-user-guide/bbduk-guide/). The sequence available at www.genome.jgi.doe.gov/PleosPC15_2/PleosPC15_2.home.html was used as a P. ostreatus genome reference to align the resulting reads STAR v2.3.16 [59]. The parameters used to achieve a single hit mapping were: --outReadsUnmapped Fastx --outFilterMismatchNoverLmax 0.04 --outFilterMultimapNmax 1. The mkPC15 v2.0 reference genome was assembled entirely in twelve scaffolds (34.3 Mb genome size) [60]. In total, 12,330 genes were annotated in this genome [61]. The expression levels were quantified using Python script rpkmforgenes.py (www.sandberg.cmb.ki.se/media/data/rnaseq/rpkmforgenes.py) to calculate values of reads per kilobase of transcript per million mapped reads $(\mathrm{RPKM})$.

\subsection{Differential gene expression analysis and gene annotation}

Differentially expressed gene (DEG) analyses were performed using the EdgeR Bioconductor package and a dispersion parameter of 0.1 . These analyses determined the transcriptional changes in the two culture conditions by comparing the gene expression values based on transcript reads. The gene expression values with $\log _{2}$ fold reads changes with a p-value $<0.01$ and an FDR (False Discovery Rate) $<0.05$ as the cut-off for statistical significance were used. A DEG with $\log _{2}$ Fold Change $\geq-2$ was established as an up-regulated gene, and $\log _{2}$ Fold Change $\leq-2$ was established as a downregulated gene.

Gene annotations were based on the JGI automated annotation to transcript identifications of the mkPC15 v2.0 reference genome. JGI automated annotation uses the following databases: Gene Ontology (GO), Kyoto Encyclopedia of Genes and Genomes (KEGG), InterPro (IPR), Eukaryotic Orthologous Groups (KOG) and Enzyme Commission numbers (EC number), Transporter Classification Database (TCDB), Carbohydrate-Active En- 
Zymes (CAZymes) and MEROPS database (proteolytic enzymes) [62]. In the case of unannotated genes, the Basic Local Alignment Search Tool (BLAST) was used to find local similarity between JGI sequences unannotated and The National Center for Biotechnology Information (NCBI) standards database sequence [63,64].

\subsection{Statistical analyses}

Minitab® version 18 software was used to construct the statistical design, evaluate statistical significance, obtain the regression models, and find the simultaneous local optimum of one or more response variables.

\subsubsection{Principal component analysis (PCA)}

A principal component analysis (PCA) was performed to explore the correlations between nutritional variables, glucose, ammonium sulfate, and yeast extract with the production of fungal biomass and laccase activity with and without copper sulfate. It was done using the data shown in the results section 3.1 (Table 3).

\subsubsection{Central Composite Design (CCD)}

The central composite experimental design allows estimating the curvature of a response surface for a chosen response variable $(\mathrm{y})$ and the terms $(\beta \mathrm{y} \varepsilon)$ of a first degree (1) or second degree (2) regression model that allows for the calculation of an optimal point.

$y=\beta_{0}+\beta_{1} x_{1}+\beta_{2} x_{2}+\varepsilon$

$y=\beta_{0}+\beta_{1} x_{1}+\beta_{2} x_{2}+\beta_{11} x_{11}^{2}+\beta_{22} x_{22}^{2}+\beta_{12} x_{1} x_{2}+\varepsilon$

Factorial ANOVAs were performed to determine the main effect and interaction effects on chosen variables on the response variable laccase activity and biomass production.

\section{Results}

\subsection{Effects of inorganic and organic nitrogen source on laccase activity}

The effect of nitrogen source and carbon-nitrogen ratio $(\mathrm{C}: \mathrm{N})$ were evaluated in submerged fermentation $(\mathrm{SmF})$ cultures of $P$. ostreatus. The composition of these culture media, fungal biomass production, final glucose concentration, and maximum laccase activity at 21 days of fungal growth are shown in Table 3 . Higher biomass production and laccase activity were obtained in cultures with YE as the nitrogen source, whereas the highest final glucose concentration, lower biomass, and laccase activities lower than 10 $\mathrm{UL}^{-1}$ were obtained when the nitrogen source was ammonium sulfate. When the nitrogen source was YE, the maximum laccase activity was 16 -fold higher on average than the observed in similar cultures with ammonium sulfate as a nitrogen source. The highest laccase activity was detected in the cultures with the highest glucose concentration $\left(20 \mathrm{gL}^{-1}\right)$ and 14:1 C:N in their composition. 
Table 3. Biological growth parameters of P. ostreatus in culture media with ammonium sulfate or yeast extract in $\mathrm{SmF}$

\begin{tabular}{|c|c|c|c|c|c|c|}
\hline $\begin{array}{l}\text { Ammo- } \\
\text { nium } \\
\text { sulfate } \\
\text { (gL-1) }\end{array}$ & $\begin{array}{c}\text { Yeast } \\
\text { Extract } \\
\left(\mathrm{gL}^{-1}\right)\end{array}$ & $\begin{array}{c}\text { Glucose } \\
\left(g^{-1}\right)\end{array}$ & $\mathrm{C}: \mathrm{N}$ & $\begin{array}{l}\text { Biomass } \\
\left(\mathrm{gL}^{-1}\right)\end{array}$ & $\begin{array}{l}\text { Final glucose } \\
\left(\mathrm{gL}^{-1}\right)\end{array}$ & $\begin{array}{c}\text { Max. laccase ac- } \\
\text { tivity } \\
\left(\mathrm{UL}^{-1}\right)\end{array}$ \\
\hline 1.0 & 0 & 0.5 & $1: 1$ & $0.26 \pm 0.02$ & $0.18 \pm 0.03$ & $2.85 \pm 2.31$ \\
\hline 1.0 & 0 & 1.0 & $2: 1$ & $0.39 \pm 0.02$ & $0.58 \pm 0.02$ & $3.40 \pm 0.58$ \\
\hline 1.0 & 0 & 10.0 & $22: 1$ & $1.30 \pm 0.18$ & $6.86 \pm 0.97$ & $6.35 \pm 3.07$ \\
\hline 10.0 & 0 & 10.0 & $2: 1$ & $1.18 \pm 0.10$ & $6.47 \pm 0.51$ & $1.74 \pm 0.15$ \\
\hline 0 & 5.0 & 1.0 & $5: 1$ & $0.91 \pm 0.04$ & $0.06 \pm 0.02$ & $944 \pm 71.6$ \\
\hline 0 & 5.0 & 10.0 & $14: 1$ & $3.62 \pm 0.01$ & $0.12 \pm 0.04$ & $489 \pm 63.2$ \\
\hline 0 & 5.0 & 20.0 & $23: 1$ & $7.65 \pm 0.08$ & $1.16 \pm 0.89$ & $104 \pm 10.1$ \\
\hline 0 & 10.0 & 20.0 & $14: 1$ & $7.04 \pm 0.18$ & $0.49 \pm 0.13$ & $2317 \pm 787.7$ \\
\hline
\end{tabular}

The results from the principal components analysis (PCA) are shown in Figure 1. Most data were grouped into three principal components that explained $93.3 \%$ of the variation in the data, with the first two dimensions (PC1 and PC2) accounting for most of the correlation of all measured variables ( $53.7 \%$ and $26.3 \%$, respectively). The maximum laccase activity correlated with the highest values of YE in the culture medium, and high initial glucose concentrations positively correlated with $\mathrm{C}: \mathrm{N}$ ratios and fungal biomass production (first component). The ammonium sulfate correlates with the highest undigested glucose left in the culture media (second component).

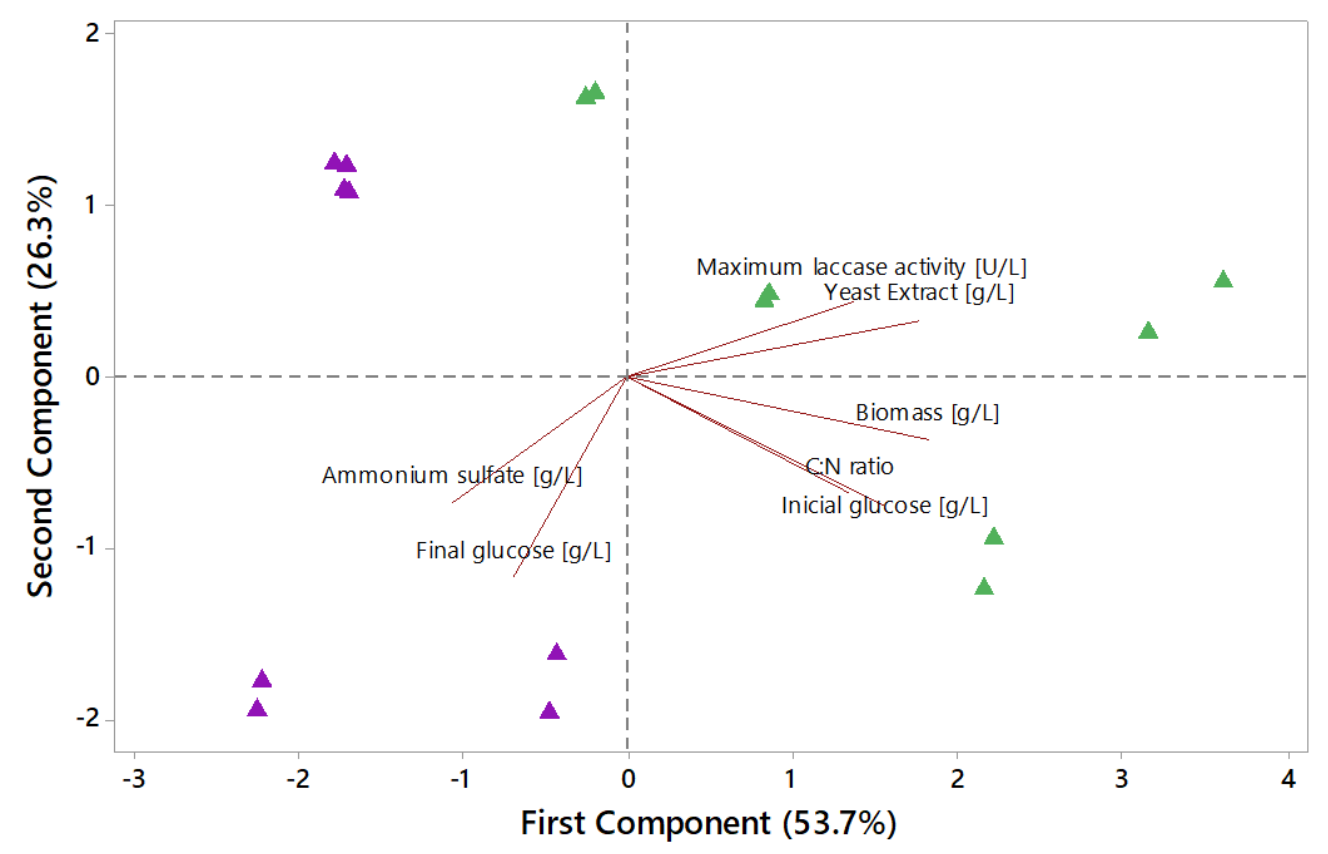

Figure 1. PCA of biological parameters of growth of P. ostreatus in culture media with ammonium sulfate or yeast extract in SmF. The purple triangles represent culture media with ammonium sulfate and the green triangles media with yeast extract.

To explore if nutrient-sufficient or nutrient-limited culture conditions induced morphological changes in the mycelium, we studied the distribution of clamp connections in apical hyphae of the fungal pellets. Figure 2 shows some representative pictures of these apical hyphae. Clamp connections in different developmental states were found in cultures containing ammonium sulfate (Figure 2, a-d) or YE (Figure 2, e-h). Differences in the hyphal shape and frequency of vacuoles were found in both apical and sub-apical cells. When YE was used, the highest nitrogen-limited condition (Figure 2, g) produced fungal 
hyphae with the highest vacuolated pattern. This nutrient-limited condition showed the lowest laccase activity among YE cultures (Table 3).

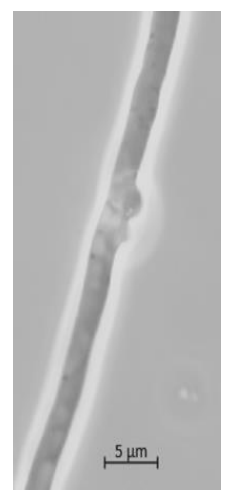

C:N 1:1

(a)

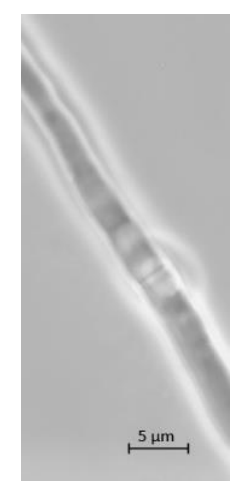

C:N 5:1

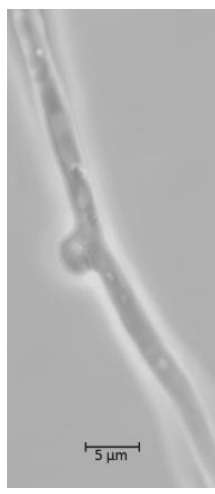

C:N 2:1

(b)

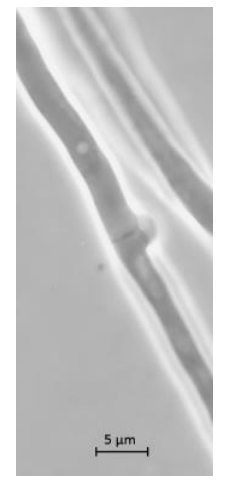

C:N 14:1

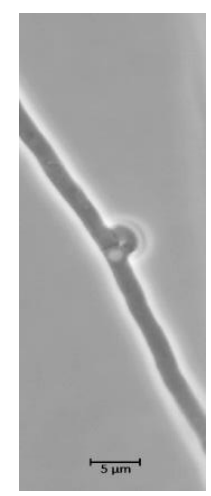

C:N 22:1

(c)

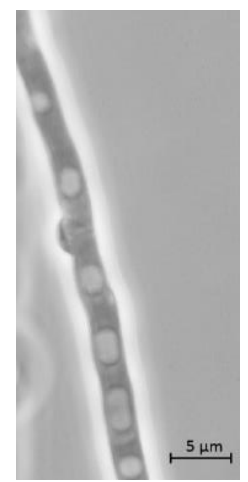

C:N 23:1

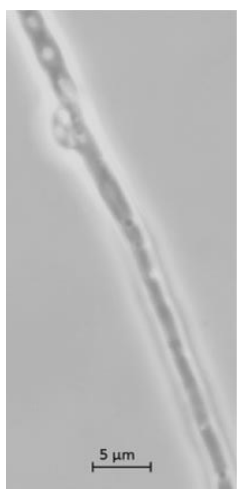

C:N 2:1

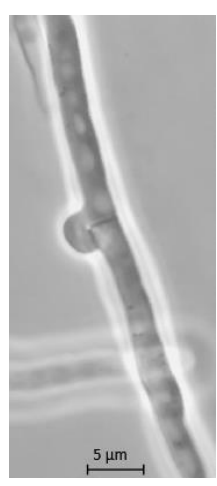

C:N 14:1

(h)

(e)

(f)

(g)

Figure 2. Clamp connection in terminal hyphae from $P$. ostreatus cultures at seven day of culture using different nutrient conditions represented as C:N ratio based on media composition: (a) Glucose-ammonium 0.5 and $1 \mathrm{gL}^{-1}$; (b) Glucoseammonium 1 and $1 \mathrm{gL}^{-1}$; (c) Glucose-ammonium 10 and $1 \mathrm{gL}^{-1}$; (d) Glucose-ammonium 10 and $10 \mathrm{gL}^{-1}$; (e) Glucose-Yeast extract 5 and $1 \mathrm{gL}^{-1}$; (f) Glucose-Yeast extract 5 and $10 \mathrm{gL}^{-1}$; (g) Glucose-Yeast extract 5 and $20 \mathrm{gL}^{-1}$; and (h) Glucose-Yeast extract 10 and $20 \mathrm{gL}^{-1}$.

Although vacuoles were observed in the hyphae when ammonium sulfate was used, the vacuolated patterns were variable. Fewer vacuoles occurred in the medium with the highest glucose concentration and the higher ratio C:N (Figure 2c) than those observed in a medium with the same glucose concentration and a lower C: $\mathrm{N}$ ratio (Figure 2d). However, laccase activity (Table 3 ) in both conditions was similar. Finally, when the vacuolation patterns of fungal hyphae from two YE nutrient-sufficient conditions were compared, both nitrogen and glucoswere needed to increase laccase activity by $P$. ostreatus. Few vacuolated hyphae were observed in the cultures with nitrogen-sufficient conditions (Figure $2 \mathrm{e})$. This condition showed the highest laccase activity per gram of biomass in the culture, while some vacuolated patterns were observed in fungal hyphae with the highest laccase activity grown in carbon-sufficient conditions (Figure $2 \mathrm{~g}$ ).

\subsection{Effect of glucose and yeast extract concentrations on laccase activity}

Different $\mathrm{YE}$ and glucose concentrations were tested to find the culture composition that maximizes biomass and laccase production in SmF cultures without or with $1 \mathrm{Mm}$ copper sulfate as a laccase inducer. The central composite experimental design (CCD) results are shown in Table 4 and Figure 3. 
Table 4. Biomass and maximum laccase activity (MLA) in culture media of P. ostreatus with different concentrations of yeast extract and glucose from a central compound design (DCC).

\begin{tabular}{|c|c|c|c|c|c|c|}
\hline \multirow{3}{*}{$\begin{array}{l}\text { Culture } \\
\text { name }^{1}\end{array}$} & \multirow{2}{*}{\multicolumn{2}{|c|}{ Factors }} & \multicolumn{4}{|c|}{ Response variables } \\
\hline & & & \multicolumn{2}{|c|}{ Without copper } & \multicolumn{2}{|c|}{$\begin{array}{l}\text { With copper sulfate } \\
1 \mathrm{mM}\end{array}$} \\
\hline & $\begin{array}{l}\text { Glucose } \\
\left(g^{-1}\right)\end{array}$ & $\begin{array}{c}\mathrm{YE} \\
\left(\mathrm{gL}^{-1}\right)\end{array}$ & $\begin{array}{c}\text { Biomass } \\
\left(\mathrm{gL}^{-1}\right)\end{array}$ & $\begin{array}{c}\log _{10} \\
\text { MLA }^{2} \\
\left(\mathrm{UL}^{-1}\right)\end{array}$ & $\begin{array}{c}\text { Biomass } \\
\left(\mathrm{gL}^{-1}\right)\end{array}$ & $\begin{array}{c}\log _{10} \\
\text { MLA }^{2} \\
\left(\mathrm{UL}^{-1}\right)\end{array}$ \\
\hline GY3008 & 30.0 & 7.50 & 9.25 & 2.69 & 10.4 & 3.82 \\
\hline GY6008 & 60.0 & 7.50 & 15.3 & 3.09 & 15.6 & 2.65 \\
\hline GY3023 & 30.0 & 22.5 & 11.2 & 2.76 & 9.71 & 4.22 \\
\hline GY6023 & 60.0 & 22.5 & 8.68 & 3.12 & 11.0 & 4.02 \\
\hline GY2415 & 23.8 & 15.0 & 12.2 & 3.18 & 10.9 & 4.17 \\
\hline GY6215 & 66.2 & 15.0 & 10.9 & 2.88 & 12.9 & 4.13 \\
\hline GY4504 & 45.0 & 4.39 & 5.29 & 1.99 & 6.13 & 2.22 \\
\hline GY4526 & 45.0 & 25.6 & 10.7 & 3.17 & 15.5 & 3.80 \\
\hline GY4515 & 45.0 & 15.0 & 16.6 & 3.11 & 22.4 & 4.50 \\
\hline GY4515 & 45.0 & 15.0 & 14.5 & 3.06 & 19.8 & 4.47 \\
\hline GY4515 & 45.0 & 15.0 & 16.9 & 3.12 & 19.4 & 4.48 \\
\hline GY4515 & 45.0 & 15.0 & 19.5 & 3.03 & 19.1 & 4.40 \\
\hline GY4515 & 45.0 & 15.0 & 16.5 & 2.99 & 19.0 & 4.41 \\
\hline
\end{tabular}

${ }^{1}$ MLA indicates the maximum laccase activity to the 21st day of culture.

${ }^{2} \mathrm{G}$ and $\mathrm{Y}$ stand for glucose and YE, respectively. The first two digits indicate the glucose concentration $\left(\mathrm{gL}^{-1}\right)$, and the last two digits indicate the $\mathrm{YE}$ concentration.

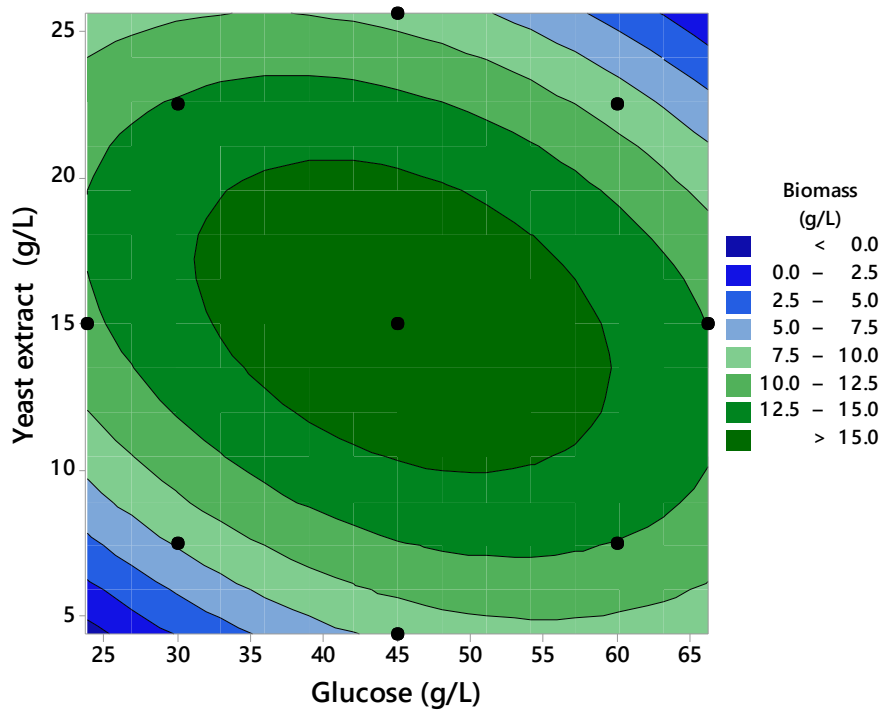

(a)

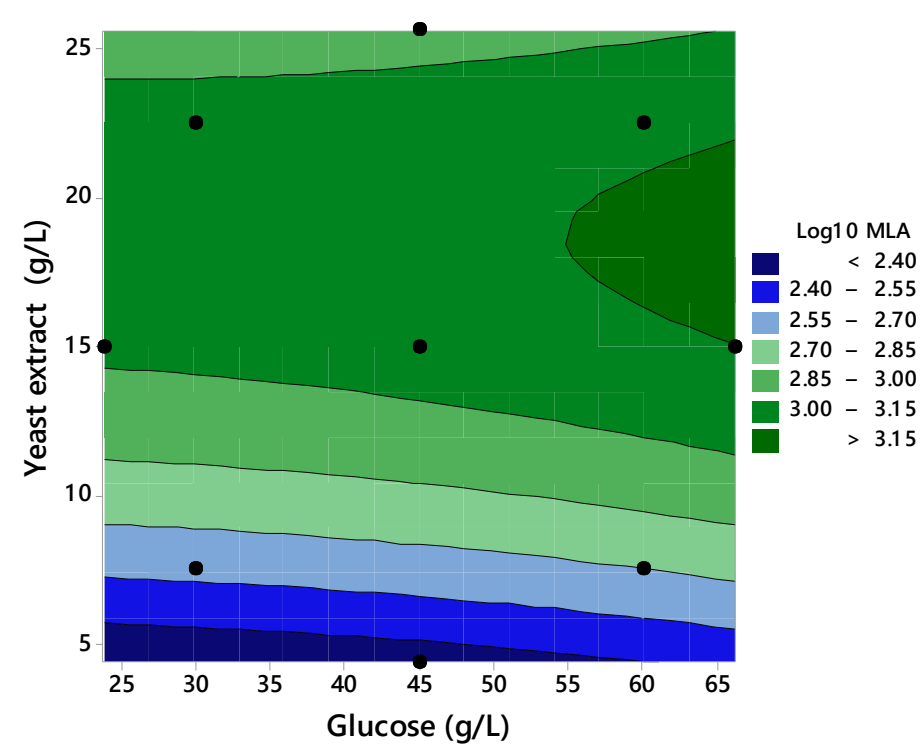

(b) 


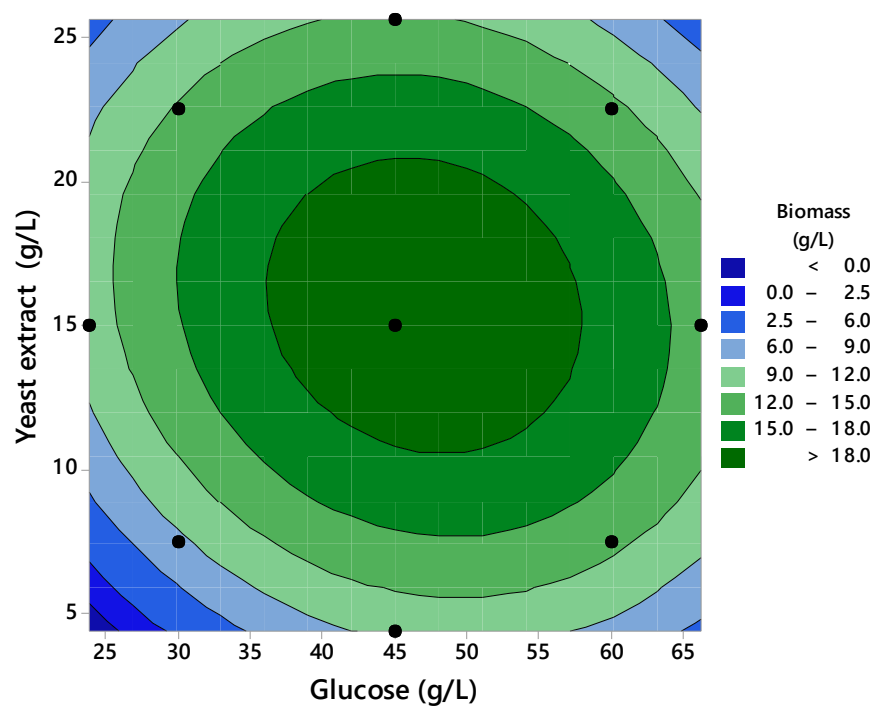

(c)

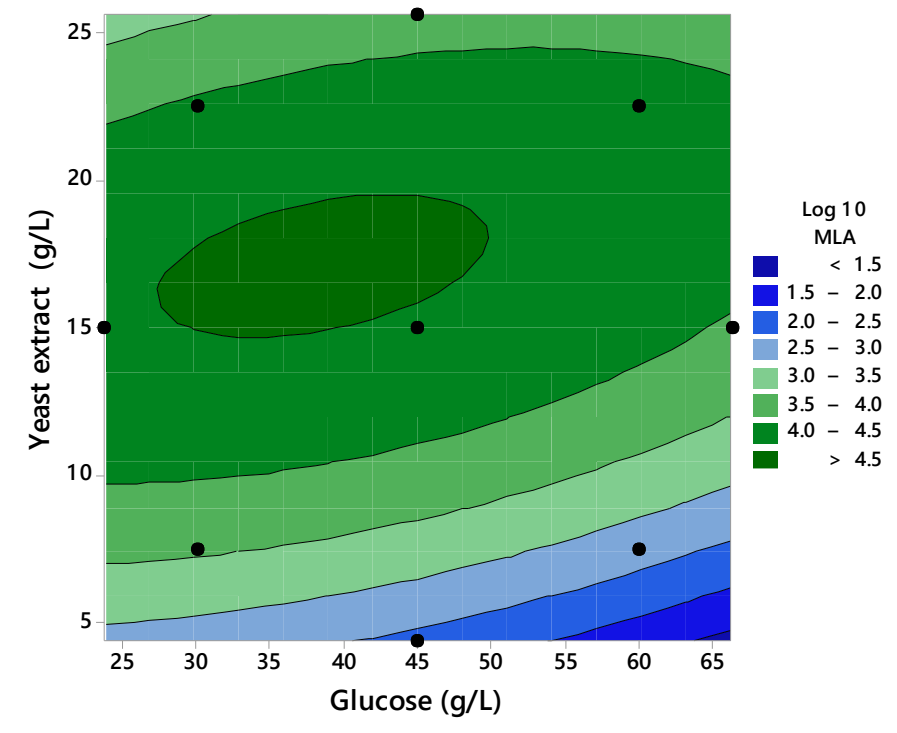

(d)

Figure 3. Contour plots of YE and glucose concentration vs. (a) Biomass production in cultures without copper sulfate; (b) Maximum laccase activity (Log $10 \mathrm{MLA}^{-1} \mathrm{UL}^{-1}$ ) production in cultures without copper sulfate; (c) Biomass production in cultures with copper sulfate; (d) Maximum laccase activity ( $\log _{10} \mathrm{MLA}_{\mathrm{U}} \mathrm{UL}^{-1}$ ) production in cultures with copper sulfate.

The CCD model fit to a quadratic model explained (p-value $<0.05$ ) the changes in biomass production as a function of glucose and YE concentrations with $\mathrm{R}^{2} 0.8231$ and 0.8035 for biomass production with and without copper sulfate, respectively. On the other hand, the laccase activity induced by copper sulfate was explained by a quadratic model ( $p$-value $<0.05)$ with glucose and YE concentration as varying factors $\left(R^{2} 0.9560\right)$; however, in the absence of a laccase inducer (i.e., the copper salt) in the culture, the media composition was statistically insignificant ( $p$-value $>0.05)$ and insufficient $\left(R^{2} 0.4039\right)$ to explain this response variable.

According to the CCD models, the contour plots (Figure 3a, c) showed that biomass production was affected by the factors square (glucose and YE concentrations), both in the absence or presence of copper sulfate. The optimum point for biomass production contained 45 and $15 \mathrm{gL}^{-1}$ glucose and YE, respectively (experiment noted as GY4515) for cultures with and without copper. Optimum biomass production in the culture medium with copper was experimentally slightly better, and the model successfully predicted this result.

In the case of maximum laccase activity (Figure 3, d), the CCD model showed that this response variable was affected by the main effect of $Y E$ concentration and the interaction between the glucose and YE concentrations. The experimental maximum laccase activity from the culture media GY4515 was close to where the model predicted the maximum laccase activity. The laccase activities from GY4515 with copper sulfate were 1.4 to 1.5 logarithmic units greater than GY4515 without copper sulfate (Figure 3, b, d).

\subsection{Characterization of the growth and laccase activity of $\underline{P}$. ostreatus under nutrient-sufficient conditions with and without copper sulfate.}

The GY4515 composition medium was selected to characterize the growth of P. ostreatus in the presence and absence of $1 \mathrm{mM}$ copper sulfate. For this characterization, biomass production, glucose consumption, total protein, and laccase activity were measured at different culture times until day 21 (Figure 4). The fungal growth profiles in both cultures (Figure 4, a) showed two phases characteristic of diauxic growth. The maximum specific growth rates $\left(\mu_{\max }\right)$ were 0.52 and $0.69 \mathrm{~d}^{-1}$ for the copper-free and copper sulfatecontaining media. Although $\mu_{\max }$ was $32 \%$ higher in the presence of copper, the total biomass produced at the end of the culture time $(21 \mathrm{~d})$ was similar in both systems (17 and $20 \mathrm{gL}^{-1}$, respectively) (Figure $4, \mathrm{a}$ ). 


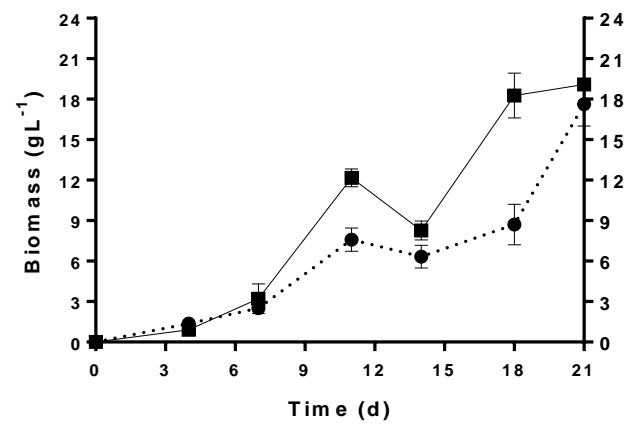

- GY4515

- $\mathrm{GY} 4515+\mathrm{Cu}^{2+}$

(a)

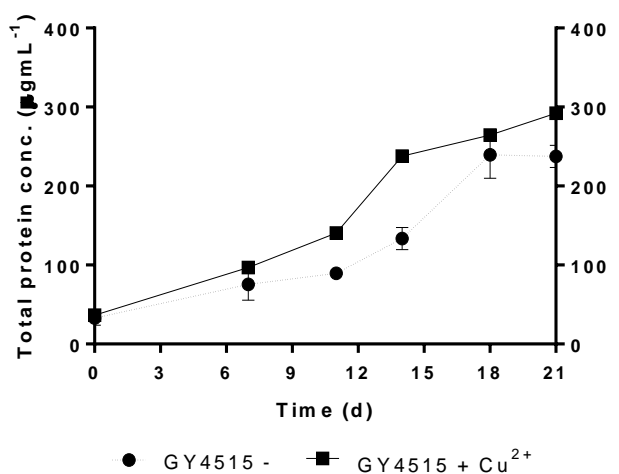

(c)

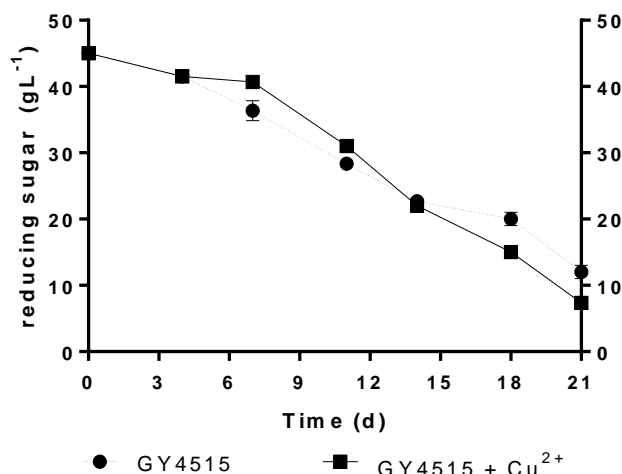

(b)

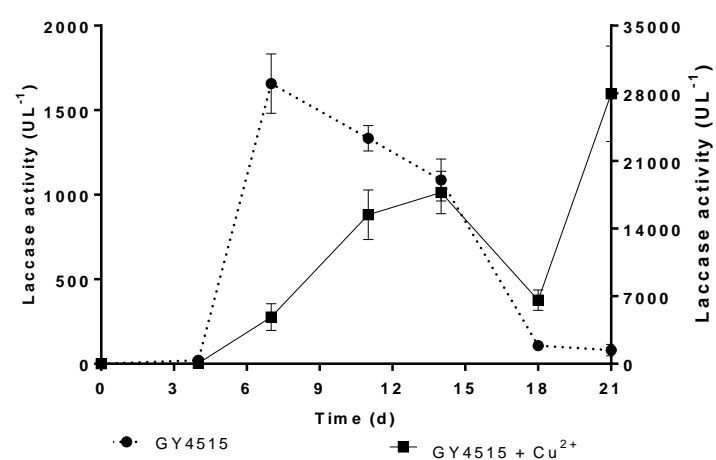

(d)

Figure 4. Growth profile of P. ostreatus in GY4515 culture media: (a) Biomass production; (b) glucose consumption; (c) total protein in culture extract; and (d) laccase activity. Black circle- discontinuous line (no copper sulfate), scale on the right. Black square -continuous line (copper sulfate $1 \mathrm{mM}$ ), left scale.

The glucose consumption profile was similar in both systems. Glucose concentration decreased with the culture time to a final glucose concentration equivalent to $20 \%$ of the initial concentration (Figure 4, b). At the same time, the total protein concentration increased in both systems. In the medium with copper sulfate, the total protein was $20 \%$ higher than in the culture media without copper (Figure 4, c).

The most significant difference between both cultures was the laccase activity profile. While the highest laccase activity values in the medium without copper sulfate were detected before day 12 , the highest activity values occurred beyond this day in the media with the laccase inducer. At the end of the culture, the laccase activity decreased in the media without copper, while it continued increasing when the inducer was present. A minimum 10-fold higher laccase activity was obtained by adding $1 \mathrm{mM}$ copper sulfate to the culture media.

\subsection{Transcriptome analysis of $\underline{\underline{P}}$. ostreatus under nutrient-sufficient conditions with and without copper sulfate.}

The top 10 more differentially expressed genes (up and down-regulated) revealed by the analysis of the $P$. ostreatus transcriptome in the GY4515 culture medium with o without copper sulfate are shown in Figure 5 and Table 5. In the cultures supplemented with copper, the laccase genes lacc10, lacc6, and lacc2 appeared among the top 10 overexpressed transcripts. Additionally, the transcripts of the small subunit of laccase POXA3a, two cupredoxin, a gene similar to the pox 2 gene, and a transcript coding for a putative copperbinding protein were also among the more overexpressed in these conditions. Conversely, in the absence of copper sulfate, the transcripts of three suspected copper transporters, a 
lipid transporter, the regulator of nitrogen metabolism Nmr, and five genes with unknown function were among the 10 most overexpressed.

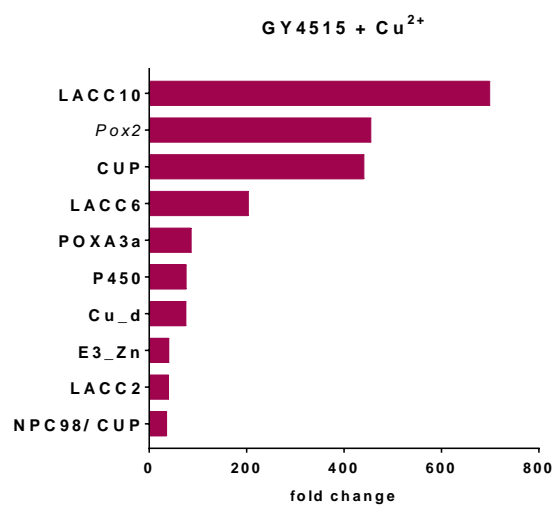

(a)

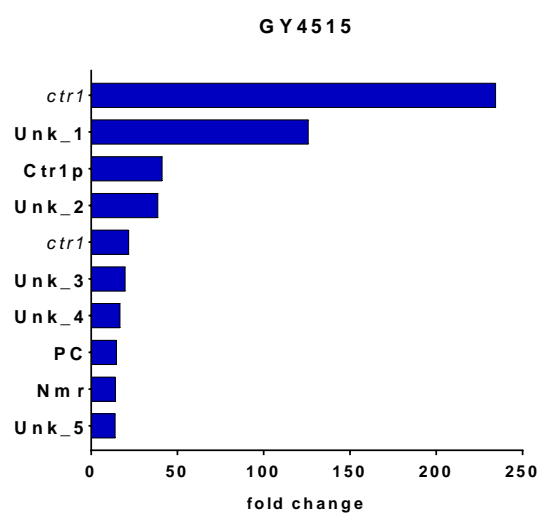

(b)

Figure 5. Differential gene expression (DGE) analysis of $P$. ostreatus in culture GY4515 vs. GY4515 + $\mathrm{Cu}^{2+}$. The top 10 of upregulated genes (a) in the presence and (b) in the absence of copper.

Table 5. Transcript identification (Id.) and JGI annotations for the top 10 DEG transcripts in $P$. ostreatus from cultures in GY4515 medium with or without copper sulfate.

\begin{tabular}{|c|c|c|c|c|c|}
\hline JGI PC15 & & & JGI PC15 & & \\
\hline $\begin{array}{c}\text { V2.0 } \\
\text { Transcript } \\
\text { Id. }\end{array}$ & $\begin{array}{l}\text { JGI Annota- } \\
\text { tions }\end{array}$ & $\begin{array}{l}\text { Short } \\
\text { name }\end{array}$ & $\begin{array}{c}\text { V2.0 } \\
\text { Transcript } \\
\text { Id. }\end{array}$ & $\begin{array}{l}\text { JGI Annota- } \\
\text { tions }\end{array}$ & $\begin{array}{l}\text { Short } \\
\text { name }\end{array}$ \\
\hline \multicolumn{3}{|c|}{ GY4515 + Cu2+ } & \multicolumn{3}{|c|}{ GY4515 } \\
\hline 1089723 & $\begin{array}{c}\text { Multicopper oxidase, } \\
\text { laccase, Lacc10 } \\
\text { (PoxC) }\end{array}$ & Lacc10 & $1095975^{1}$ & $\begin{array}{l}\text { Unannotated gen. } \\
\text { Similar to ctr1 gene } \\
\text { for copper trans- } \\
\text { porter, exons 1-3 } \\
\text { Pleurotus sp. 'Flor- } \\
\text { ida }\end{array}$ & ctr1 \\
\hline $1105204^{1}$ & $\begin{array}{l}\text { Unannotated gen. } \\
\text { Similar to Phenol ox- } \\
\text { idase (pox2) gene }\end{array}$ & Pox2 & 159791 & Unknown protein & Unk_1 \\
\hline 1097654 & Cupredoxin domin & Cup & 1092022 & $\begin{array}{c}\text { Copper transporter, } \\
\text { Ctr1p }\end{array}$ & Ctr1p \\
\hline 1113032 & $\begin{array}{c}\text { Multi-copper oxi- } \\
\text { dase Laccase,Lacc6 } \\
\text { (PoxA1b) }\end{array}$ & Lacc6 & 1086646 & Unknown protein & Unk_2 \\
\hline 1067572 & $\begin{array}{l}\text { Small subunit of lac- } \\
\text { case PoxA3a }\end{array}$ & РoxA3a & $1088435^{1}$ & $\begin{array}{l}\text { Unannotated gen. } \\
\text { Similar to ctr1 gene } \\
\text { for copper trans- } \\
\text { porter, exons 1-3 } \\
\text { Pleurotus sp. 'Flor- } \\
\text { ida }\end{array}$ & ctr1 \\
\hline 1063469 & $\begin{array}{l}\text { Cytochrome P450 } \\
\text { CYP2 subfamily }\end{array}$ & P450 & 1090041 & Unknown protein & Unk_3 \\
\hline 1087630 & $\begin{array}{l}\text { Blue (type 1) copper } \\
\text { domain }\end{array}$ & $\mathrm{Cu}-\mathrm{d}$ & 1090781 & Unknown protein & Unk_4 \\
\hline 1105457 & $\begin{array}{l}\text { Predicted E3 ubiqui- } \\
\text { tin ligase/Zinc fin- } \\
\text { ger, C3HC4 type }\end{array}$ & E3_Zn & 1099858 & Polyketide cyclase & PC \\
\hline 1067328 & $\begin{array}{l}\text { Multi-copper oxi- } \\
\text { dases, Lacc2 }\end{array}$ & Lacc2 & 171939 & NmrA-like family & $\mathrm{Nmr}$ \\
\hline 1062660 & $\begin{array}{c}\text { Nuclear pore com- } \\
\text { plex, Nup98 compo- } \\
\text { nent (sc } \\
\text { Nup145/Nup100/Nu }\end{array}$ & $\begin{array}{l}\text { NPC98/C } \\
\text { up }\end{array}$ & 1077411 & Unknown protein & Unk_5 \\
\hline
\end{tabular}


p116), and Cupre-

doxin domain

${ }^{1}$ The Basic Local Alignment Search Tool (BLAST) from The National Center for Biotechnology
Information (NCBI) standards database sequences was used to find local similarity between JGI
sequences unannotated.

3.5. Analysis of laccase gene transcripts

The relative quantification of the transcripts of the 12 laccase genes annotated in the $P$. ostreatus genome was carried out to determine the genes responsible for the activity in the GY4515 medium with and without copper sulfate. In Figure 6, the results show that in the absence of copper sulfate, the lacc2 gene transcript was the only one significantly detected, while in the presence of this laccase inducer, the lacc2, lacc6, and lacc10 gene transcripts were the most highly up-regulated. To a lesser extent, the transcripts of lacc3 and lacc5 genes were also overexpressed in the presence of copper sulfate. The lacc 8 gene could not be amplified.

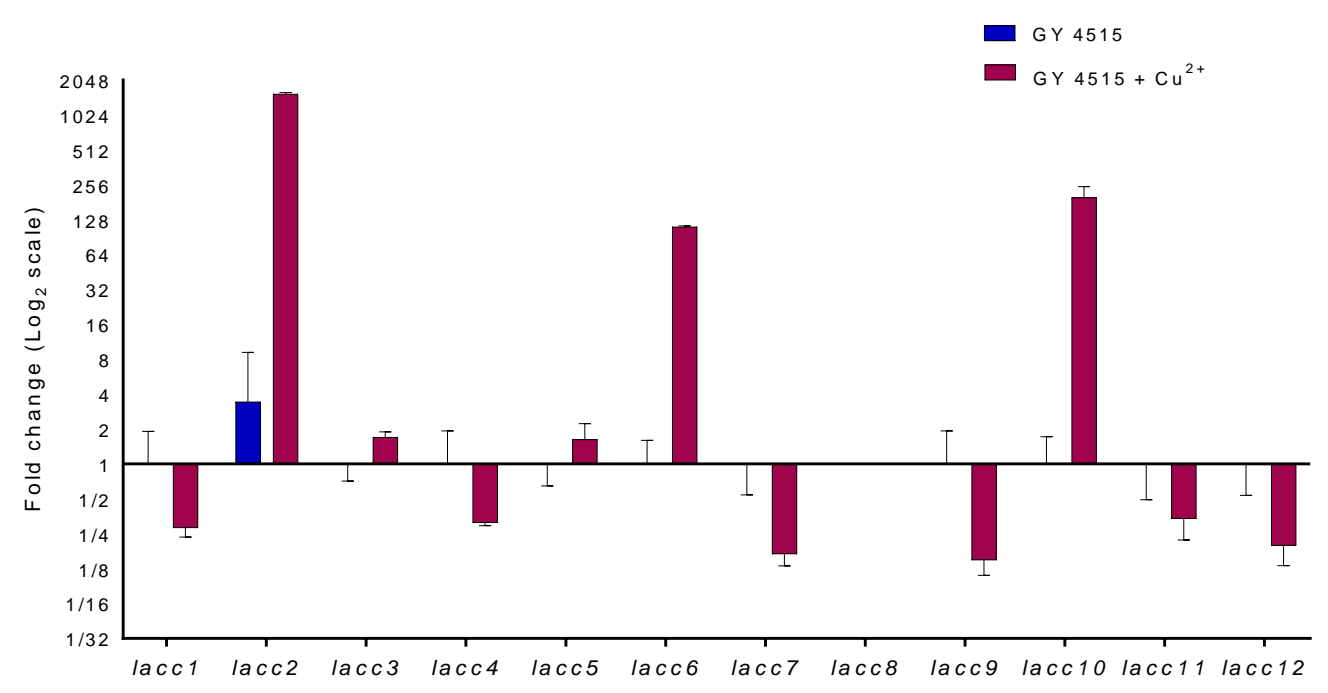

Figure 6. Relative quantification to the 12 P. ostreatus laccase genes in GY4515 medium on day 12 of culture. Blue bar: GY4515 without copper sulfate. Red bar: GY4515 with copper sulfate, 1mM.

\subsection{Effect limited-nutrition conditions on laccase production}

As copper-induced laccase activity depended on both glucose and YE concentration, the effects of copper in nutrient-limited conditions were tested. For this, two cultures in nutrient-limited conditions, carbon- and nitrogen-limited conditions, were chosen: the carbon-limited medium was $5.0 \mathrm{gL}^{-1}$ glucose, and $15 \mathrm{gL}^{-1} \mathrm{YE}$ (GY0515), whereas the nitrogen-limited medium was $45 \mathrm{gL}^{-1}$ glucose, and YE, $4.0 \mathrm{gL}^{-1}$ (GY4504). Figure 7 shows the electrophoretic migration of the laccase activity recovered from the supernatant of the GY4515, GY0515, and GY4504 media at two culture times, 12 and 21days, in the absence and presence of copper. 


\section{GY4515-12 GY0515-12 GY4504-12 GY4515-21 Culture medium-day

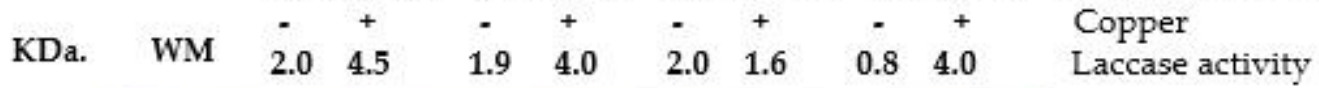

70

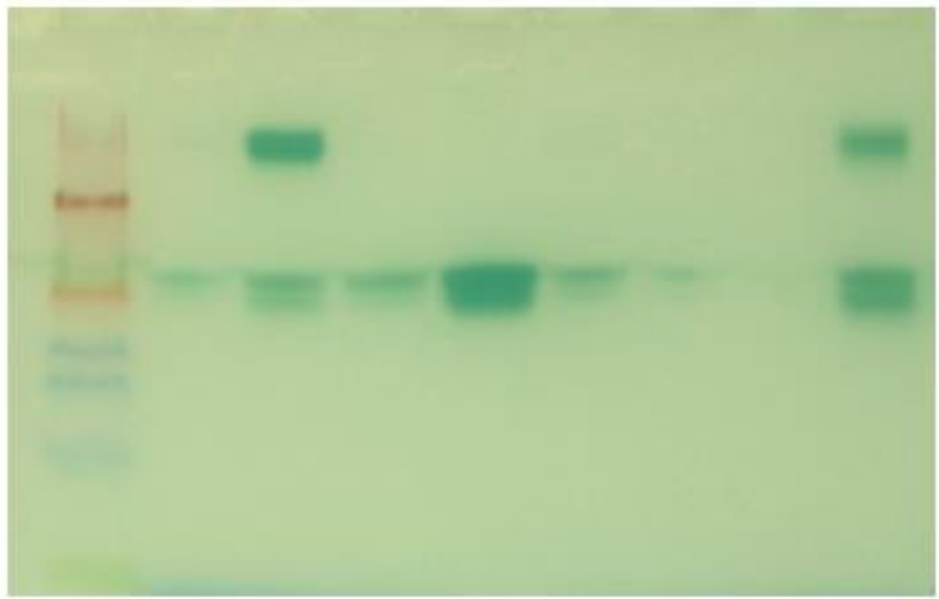

Figure 7. Zymogram of laccases in the supernatant in culture media with different nutrient conditions at 12 or 21 days of culture. Lane 1. Molecular weight marker (WM). Left to right. Lane 2-3 nutrient-sufficient condition GY4515 day 12 (GY4515). Lane 4-5 carbon-limited condition GY0515 day 12 (GY515). Lane 6-7 nitrogen-limited condition GY4504 day 12 (GY4504). Lane 8-9 nutrient-sufficient condition GY4515 day 21 (GY4515-21). Medium without copper (-), with copper (+). Laccase activity is presented as $\log _{10}\left(\mathrm{UL}^{-1}\right)$.

In the zymogram (Figure 7), the migration patterns and intensity of the bands changed depending on the presence or absence of copper sulfate, the composition of the culture medium, and the culture day. In the absence of copper sulfate, only two weak bands sized around $40 \mathrm{kDa}$ were present, which coincide with the laccase activity for all these extracts cultures on day 12th of culture around two logarithmic units. The addition of copper sulfate to the nutrient-sufficient medium, GY4515, revealed four bands, two at $70 \mathrm{kDa}$ and the other at $40 \mathrm{kDa}$ (lanes 3 and 9). In these cultures, the laccase activities recovered on days $12^{\text {th }}$ and $21^{\text {st }}$ were more than four logarithmic $\mathrm{UL}^{-1}$ (Figure 7, lane 3 and 9). Under carbon-limitation (GY0515), only two strong bands appeared at $40 \mathrm{kDa}$. In this condition, the laccase activity was around two logarithmic units higher in the coppercontaining than in the copper-lacking medium. In contrast, in the nitrogen-limited cultures GY4504, the addition of copper sulfate was insufficient to increase laccase activity. For these cultures, only one weak band appeared at $40 \mathrm{kDa}$.

\subsection{Hyphal morphology of $\underline{P}$. ostreatus under different nutrient conditions with copper}

The hyphal morphology was observed in three selected nutrient conditions with copper: nutrient-sufficient (GY4515), carbon-limited (GY0515), and nitrogen-limited (GY4504). The micrographs of the clamp connections in terminal fungal hyphae at seven days of culture are shown in Figures 8. The results showed that fungal hyphae from all nutrient conditions medium had clamp connections as expected for a dikaryotic strain. Fungal hyphae in nutrient-sufficient condition, GY4515, were no-vacuolated, whereas some level of vacuolation was observed in both nutrient-limited conditions. In hyphae from the carbon-limited medium, GY0515, this level vacuolated pattern was barely observed, while it was clear in hyphae from the nitrogen-limited medium, GY4504 


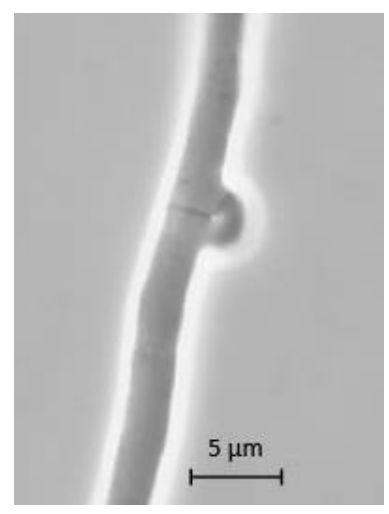

(a)

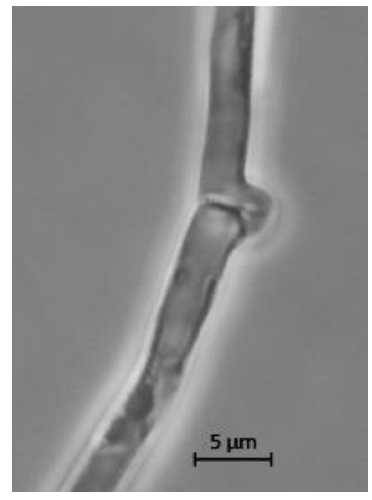

(a)

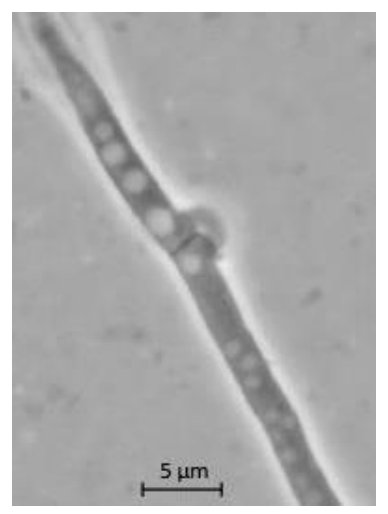

(c)

Figure 8. Clamps connections in terminal hyphae of $P$. ostreatus in culture media with different nutrient conditions and copper sulfate $1 \mathrm{mM}$ at the $7^{\text {th }}$ culture day: (a) nutrient-sufficient condition, GY4515 + $\mathrm{Cu}^{2+}$; (b) carbon-limited condition, GY0515 + $\mathrm{Cu}^{2+}$; (c) nitrogen-limited condition GY4504 + $\mathrm{Cu}^{2+}$.

\section{Discussion}

Systematic research on the interactions between nutritional factors on laccase activity production by $P$. ostreatus cultivated on natural substrates is currently scarce; therefore, this work was aimed to consider the interaction between two nutritional factors (carbon and nitrogen concentration) and copper sulfate at $1 \mathrm{mM}$ to determine how the medium composition affects laccase induction by copper in submerged fermentation. Increased fungal biomass production is usually a sign of sufficient nutrient conditions when carbon and nitrogen sources are assimilable in the culture media in the presence of sufficient concentration of other growth factors. Our study chose two nitrogen sources (ammonium sulfate and YE) to establish which one best increased fungal biomass production and laccase activity in Smf. This approach allowed comparing the performance of nutrient-sufficient, only carbon-sufficient, and only nitrogen-sufficient conditions and assessing laccase activity in the culture media in the absence or presence of laccase-inducing copper sulfate.

YE was a more assimilable nitrogen source than ammonium sulfate to stimulate biomass and laccase activity in the evaluated culture media conditions; therefore, in subsequent experimentation, glucose and YE concentrations were varied using a central composite experimental design, which applies in the surface response methodology, to optimize the composition of the culture medium for optimal laccase activity. It was found that glucose and YE concentrations do not sufficiently explain the laccase activity in cultures without copper inducer; however, when copper sulfate is in the culture media, both glucose and YE concentrations influence this enzymatic activity causing an increase of around a 20 fold. Furthermore, from this analysis, it is possible to infer that the organic nitrogen-sufficient conditions increment laccase production.

Laccase activity in $P$. ostreatus and other white-rot fungi has been frequently reported to be affected by nitrogen sources [65]. Therefore, we tested the effect of ammonium sulfate and yeast extract on laccase activity. We tested different nitrogen sources and C:N ratios. Because the lower $\mathrm{C}: \mathrm{N}$ ratio indicates more nitrogen disponibility than higher $\mathrm{C}: \mathrm{N}$ ratios in the culture, our results suggest that laccase activity is dependent on carbon-sufficient and nitrogen-sufficient conditions. Besides that, ammonium sulfate was insufficient to increase laccase activity at different nutrient concentrations (C:N ratio). Using yeast extract as a nitrogen source, the magnitude of laccase activity seems to depend on glucose concentration and C:N ratio. Although in other studies, the increase of ammonium sulfate concentration increased laccase activity in the culture [66], the positive effect of a lower C:N ratio (nitrogen - sufficient conditions) seems to depend on the complex carbon source and the culture in solid-state fermentation (SSF) [67]. On the contrary, we found a positive effect of yeast extract on laccase activity. This positive effect was also reported in both SmF [68] and SSF [69].

The profiles of fungal growth, laccase activity, laccase gene family expression, and genome-wide gene transcription were studied using high-resolution techniques such as 
Real-time qPCR and RNA-seq in the culture medium composition with sufficient carbon and nitrogen. The time course of laccase production during the culture was different in the presence or absence of copper, suggesting that the regulatory mechanisms of laccase activity production are different in both systems. Comparisons showed that the main change in $P$. ostreatus growth with and without copper was laccase activity by the copperinduction of three laccase genes, lacc2, lacc6, and lacc10. At the transcriptional level, fungal growth without copper overexpressed copper transporter of high affinity (ctr1) and the transcriptional factor, Nitrogen Metabolic Repression ( $\mathrm{nmr}$ ), a signal of nitrogen sufficient condition. Nitrogen-sufficient conditions could mainly regulate the crt1 expression because, in nitrogen-limited conditions, laccase inducing by copper sulfate was lower than carbon-limited conditions.

The transcriptome data also suggest that, in the GY4515 medium, the yeast extract and the concentration used could induce the metabolic repression of nitrogen. This result is corroborated by the overexpression of a transcript with an NMR-like domain. These results suggest repression by nitrogen could be related to the regulation of copper transporters that, once present in the culture medium, facilitate the entry of this metal into the fungal cell and induce the transcription of genes lacc2, lacc6, and lacc10. Furthermore, the $P$. ostreatus transcriptome from the GY4515 culture medium with copper sulfate revealed that the lacc2, lacc6, and lacc10 genes responded to the addition of this laccase inducer under nutrient-sufficient conditions.

We explored the fungal microscopic-morphological changes in terminal hyphae, identified by the distal clamps connections, in culture media using ammonium sulfate or yeast extract. We observed interesting microscopic-morphological changes according to the sources of nitrogen and the C:N ratios. A large pattern of vacuoles was found using yeast extract. This behavior has also been observed in hyphae of $C$. albicans cultivated in nutrient-rich media, which showed fewer vacuolated compartments compared to the hyphae grown in low nitrogen media. Compared to that reported for this pleomorphic fungus, our results are similar [70]. The P. ostreatus hyphae grown in nutrient-rich media had fewer vacuolated compartments similar to those reported for C. albicans. Our study showed more vacuolated compartments grown in media with low nitrogen content in the culture media with higher C:N ratios. In another study, P. ostreatus was cultured in PotatoDextrose-YE (PDY). The pellets from the culture media showed a young mycelium barely vacuolated (at the $5^{\text {th }}$ culture day); however, when glucose concentration decreased for the culture time, the old mycelium was vacuolated (at the $12^{\text {th }}$ culture day) [28]. Therefore, those vacuolated patterns in the young mycelium of $P$. ostreatus in SmF seem to signal nutrient-limitation in this fungus that could affect laccase activity.

Another sign of nutrient-sufficient conditions for carbon and nitrogen was tested, a culture medium whose composition increased biomass production using only glucose and YE in the culture medium. At the same time, the effect of glucose and YE concentrations on laccase activity in the absence and presence of $1 \mathrm{mM}$ copper sulfate was also evaluated. The GY4515 medium was the composition closest to the maximum biomass production predicted by the statistical model. Surprisingly, the effect of the nutrient conditions in laccase activity was strongly dependent on copper sulfate in the culture medium.

Without copper sulfate, the glucose and YE concentrations were insufficient to explain the changes in laccase activity in the different culture media evaluated in this study. However, increasing the glucose concentration from 5 to $2 \mathrm{gL}^{-1}$ resulted in a more than five-fold increase in laccase activity. An additional increase of up to $40 \mathrm{gL}^{-1}$ in glucose concentration did not improve the laccase activity. On the contrary, lower activities were obtained [71]. In reports for another fungus, Cerrena sp., high carbon and nitrogen concentrations in the fermentation medium were beneficial for laccase production. In contrast, regardless of carbon concentration, low nitrogen concentrations drastically reduced laccase production [72]. However, the composition of the culture medium had little influence on laccase activity in $P$. ostreatus nutrient-sufficient conditions when the fungus grew 
in a culture medium with a lot of glucose $102.68 \mathrm{gL}^{-1}$ and yeast extract $43.65 \mathrm{gL}^{-1}$ concentrations, where the lignocellulosic biomass pretreatment and laccase activity improved the pretreatment system [73].

With copper sulfate, the changes in laccase activity in the different culture media were statistically explained by the glucose and YE concentrations evaluated using a CCD. Here we only tested a fixed concentration of copper sulfate $(1 \mathrm{mM})$ because this was the concentration that had the highest increase in laccase activity when different copper sulfate concentrations ( 0.5 to $5 \mathrm{mM}$ ) were tested in P. ostreatus in SmF [74]. In other studies in P. ostreatus and other fungi, the design of experiments (DOE) of response surface methodology was also used; however, copper sulfate and nutritional factors were tested at various concentrations $[69,71,75-78]$. Despite this, the main finding was similar to the finding in this study: nutritional factors, mainly organic nitrogen source and copper concentrations, showed an interaction effect that increased the laccase activity considerably in the culture media. Therefore, evidence was collected to infer that fungal biomass in nutrientsufficient conditions is more susceptible to laccases inducers than nutrient-limited culture conditions. However, when the profile of P. ostreatus growth in GY4515 was characterized with and without copper, the main difference was laccase activity. Furthermore, the local transcriptional analysis of the laccase gene family showed that lacc2, lacc6, and lacc10 were overexpressed in the culture with copper.

The Zymogram results indicate that the isoenzymes induced by copper are affected by different nutrient conditions. In nitrogen-sufficient conditions that are also carbon-limited, the expression of isoenzymes around 70KDa (Presumably lacc6) is negatively affected, while the isoenzymes Lacc2 and Lacc10 (around $40 \mathrm{KDa}$ ) are positively affected. All isoenzymes induced by copper were negatively affected in the inverse nutrients conditions (i.e., in carbon-sufficient conditions and nitrogen-limited). These results show an important effect of nitrogen-limited laccase activity induced by copper, suggesting that processes associated with organic nitrogen metabolisms influence copper uptake. In contrast, in nitrogen-sufficient that are simultaneously, the carbon-limited conditions, only some specific laccase isoenzymes induced by copper are affected. In these carbon-limited conditions, laccase activity is still influenced by copper because there is probably copper uptake.

Copper-induced laccase isoforms enzymes were previously identified in SmF [79]. The most abundantly secreted with the highest migration pattern Lacc10 (PoxC), then Lacc2 (PoxA3) showed an intermediate migration pattern [17], and Lacc6 (PoxA1b) was the one that presented the lowest migration pattern [56]. However, the zymogram analysis in this study showed four laccase isoenzymes. The transcriptome analysis found lacc2, lacc6, lacc10, pox2, and PoxA3a among the top 10 overexpressed transcripts. This last transcript does not code for a laccase enzyme but for a protein that can form heterodimers with Lacc2 (PoxA3) [17], [80]. We do not know if any laccase heterodimeric was present in the analyzed enzymatic crude extract; however, four bands in the zymogram analysis suggest Lacc6, Lacc2, Lacc10, and another isoform.

It is noteworthy to observe how these isoforms changed in the nutrient-limited conditions in the culture medium. In carbon-limited conditions, the two bands at $70 \mathrm{KDa}$ disappeared, while in nitrogen-limited conditions, two bands at $70 \mathrm{KDa}$ and two bands at 40 KDa were drastically affected. These results may support the idea that nutrient-sufficient conditions confer the fungus more susceptibility to laccase inducers. A marker for nutrient-sufficient conditions was found on the nmr1-like transcript listed in the top ten transcripts in culture without copper. In these nutrient-sufficient conditions, three ctr 1 copper transporters were also found. This copper transporter has already been shown to negatively regulate CTR1 transcription in the dikaryon strain dkN001 and its monokaryon parents mkPC9 and mkPC15 of P. ostreatus [81].

Finally, using different nitrogen sources and C.N ratios allowed us to observe that nitrogen-limited conditions had a stronger relationship with the vacuolated patterns. 
Moreover, nitrogen-limited conditions affected laccase induction by copper. All these results again suggest a likely relationship between nitrogen metabolisms and copper uptake. In this relationship, $P$. ostreatus in initial nitrogen-limited conditions medium produce hyphal with vacuolated morphology. These hyphal could have a lower expression level of copper transporters such as ctr1 than hyphal obtained in the nitrogen- sufficient condition. Consequently, copper uptake mechanisms are less prevalent in nitrogen-limited than in nitrogen-sufficient conditions, affecting laccase genes regulation by transcriptional mechanisms in the cis-acting elements promoter sequences as metal responsive elements (MRE) [12].

\section{Conclusions}

This study describes a systematic analysis of the composition of the culture medium based on two nutritional factors, glucose as a carbon source and ammonium sulfate or yeast extract as nitrogen sources. This analysis determined what type of nitrogen source and what combination of glucose and yeast extract concentrations favored the production of fungal biomass and laccase activity induced by copper. The nutrient-sufficient conditions for both carbon and nitrogen in P. ostreatus cultures favored the expression of a transporter family of genes with a high affinity to copper: the CTRs, which were able to incorporate copper from the environment. This effect was evidenced by an increase in copperdependent laccase activity by 20 fold, the presence of four laccase isoforms that were detectable in zymogram, and by an increase of three laccase transcripts lacc2, lacc6, and lacc10 determined by real-time qPCR and RNAseq.

\section{Supplementary Materials: There is no supplementary material}

Author Contributions: D.D-S conceptualization, formal analysis, methodology, writing original draft, writing, reviewing and editing. DS and EM formal analysis. MA formal analysis, data curation. GP formal analysis, data curation. AGP supervision, writing review and editing. RS supervised the experimental work and the production of the paper. LR and RS were responsible for funding acquisition.

Funding: This research was funded by project number RTI2018-099371-B-I00 (MCIU, AEI, FEDER/UE) of the Spanish National Research Plan, and Public University of Navarre (UPNA) funds. DD-S was supported by funds of the Gobernación del Departamento del Cesar by the Ministerio de Ciencia y Tecnología en Innovación de Colombia through 681 of 2014 resolution.

Institutional Review Board Statement: Not applicable.

Informed Consent Statement: Not applicable.

Data Availability Statement: The data presented in this study are available on request from the corresponding author. The data are not publicly available because other data from these wholegenome transcriptomes are being used for other analyses to be published independently of this one

Acknowledgments: The author thankfully acknowledges the computer resources, technical expertise, and assistance provided by the SCBI (Supercomputing and Bioinformatics) center of the University of Malaga.

Conflicts of Interest: The authors declare no conflict of interest. The funders had no role in the design of the study, in the collection, analyses, or interpretation of data, in the writing of the manuscript, or in the decision to publish the results.

\section{References}

1. Giardina, P.; Faraco, V.; Pezzella, C.; Piscitelli, A.; Vanhulle, S.; Sannia, G. Laccases: A never-ending story. Cell. Mol. Life Sci. 2010, 67, 369-385, doi:10.1007/s00018-009-0169-1.

2. Sirim, D.; Wagner, F.; Wang, L.; Schmid, R.D.; Pleiss, J. The Laccase Engineering Database: A classification and analysis system for laccases and related multicopper oxidases. Database 2011, 2011, 1-7, doi:10.1093/database/bar006.

3. Asemoloye, M.D.; Marchisio, MA; Gupta, V.K.; Pecoraro, L. Genome-based engineering of ligninolytic enzymes in fungi. Microb. Cell Fact. 2021, 20, 1-18, doi:10.1186/s12934-021-01510-9. 
4. Mate, DM; Alcalde, M. Laccase: a multi-purpose biocatalyst at the forefront of biotechnology. Microb. Biotechnol. 2017, 10, 14571467, doi:10.1111/1751-7915.12422.

5. Sun, K.; Li, S.; Si, Y.; Huang, Q. Advances in laccase-triggered anabolism for biotechnology applications. Crit. Rev. Biotechnol. 2021, doi:10.1080/07388551.2021.1895053.

6. Fernández-Fueyo, E.; Ruiz-Dueñas, F.J.; López-Lucendo, M.F.; Pérez-Boada, M.; Rencoret, J.; Gutiérrez, A.; Pisabarro, A.G.; Ramírez, L.; Martínez, A.T. A secretomic view of woody and nonwoody lignocellulose degradation by Pleurotus ostreatus. Biotechnol. Biofuels 2016, 9, 1-18, doi:10.1186/s13068-016-0462-9.

7. Sánchez, C. Cultivation of Pleurotus ostreatus and other edible mushrooms. Appl. Microbiol. Biotechnol. 2010, 85, 1321-1337, doi:10.1007/s00253-009-2343-7.

8. Ohm, R.A.; Riley, R.; Salamov, A.; Min, B.; Choi, I.G.; Grigoriev, I. V. Genomics of wood-degrading fungi. Fungal Genet. Biol. 2014, 72, 82-90, doi:10.1016/j.fgb.2014.05.001.

9. Kues, U.; Ruhl, M. Multiple Multi-Copper Oxidase Gene Families in Basidiomycetes - What for? Curr. Genomics 2011, 12, 7294, doi:10.2174/138920211795564377.

10. Castanera, R.; Omarini, A.; Santoyo, F.; Pérez, G.; Pisabarro, A.G.; Ramírez, L. Non-Additive Transcriptional Profiles Underlie Dikaryotic Superiority in Pleurotus ostreatus Laccase Activity. 2013, 8, doi:10.1371/journal.pone.0073282.

11. Pérez, G.; Pangilinan, J.; Pisabarro, A.G.; Ramírez, L. Telomere organization in the ligninolytic basidiomycete pleurotus ostreatus. Appl. Environ. Microbiol. 2009, 75, 1427-1436, doi:10.1128/AEM.01889-08.

12. Piscitelli, A.; Giardina, P.; Lettera, V.; Pezzella, C.; Sannia, G.; Faraco, V. Induction and transcriptional regulation of laccases in fungi. Curr. Genomics 2011, 12, 104-112, doi:10.2174/138920211795564331.

13. Pezzella, C.; Autore, F.; Giardina, P.; Piscitelli, A.; Sannia, G.; Faraco, V. The Pleurotus ostreatus laccase multi-gene family: Isolation and heterologous expression of new family members. Curr. Genet. 2009, 55, 45-57, doi:10.1007/s00294-008-0221-y.

14. Jiao, X.; Li, G.; Wang, Y.; Nie, F.; Cheng, X.; Abdullah, M.; Lin, Y.; Cai, Y. Systematic analysis of the pleurotus ostreatus laccase gene (PoLac) Family and functional characterization of PoLac2 involved in the degradation of cotton-straw lignin. Molecules 2018, 23, 880, doi:10.3390/molecules23040880.

15. Castanera, R.; Pérez, G.; Omarini, A.; Alfaro, M.; Pisabarro, A.G.; Faraco, V.; Amore, A.; Ramírez, L. Transcriptional and enzymatic profiling of pleurotus ostreatus laccase genes in submerged and solid-state fermentation cultures. Appl. Environ. Microbiol. 2012, 78, 4037-4045, doi:10.1128/AEM.07880-11.

16. Pezzella, C.; Lettera, V.; Piscitelli, A.; Giardina, P.; Sannia, G. Transcriptional analysis of Pleurotus ostreatus laccase genes. Appl. Microbiol. Biotechnol. 2013, 97, 705-717, doi:10.1007/s00253-012-3980-9.

17. Giardina, P.; Autore, F.; Faraco, V.; Festa, G.; Palmieri, G.; Piscitelli, A.; Sannia, G. Structural characterization of heterodimeric laccases from Pleurotus ostreatus. 2007, 1293-1300, doi:10.1007/s00253-007-0954-4.

18. Faraco, V.; Ercole, C.; Festa, G.; Giardina, P.; Piscitelli, A.; Sannia, G. Heterologous expression of heterodimeric laccase from Pleurotus ostreatus in Kluyveromyces lactis. Appl. Microbiol. Biotechnol. 2008, 77, 1329-1335, doi:10.1007/s00253-007-1265-5.

19. Giardina, P.; Palmieri, G.; Scaloni, A.; Fontanella, B.; Faraco, V.; Cennamo, G.; Sannia, G. Protein and gene structure of a blue laccase from Pleurotus ostreatus. Biochem. J. 1999, 341, 655-663, doi:10.1042/0264-6021:3410655.

20. Macellaro, G.; Baratto, M.C.; Piscitelli, A.; Pezzella, C.; Biani, F.F. De; Palmese, A.; Piumi, F.; Record, E.; Basosi, R.; Sannia, G. Effective mutations in a high redox potential laccase from Pleurotus ostreatus. 2014, 4949-4961, doi:10.1007/s00253-013-5491-8.

21. Aza, P.; De Salas, F.; Molpeceres, G.; Rodríguez-Escribano, D.; De La Fuente, I.; Camarero, S. Protein engineering approaches to enhance fungal laccase production in S. cerevisiae. Int. J. Mol. Sci. 2021, 22, 1-19, doi:10.3390/ijms22031157.

22. Maestre-Reyna, M.; Liu, W.C.; Jeng, W.Y.; Lee, C.C.; Hsu, C.A.; Wen, T.N.; Wang, A.H.J.; Shyur, L.F. Structural and functional roles of glycosylation in fungal laccase from lentinus sp. PLoS One 2015, 10, 1-28, doi:10.1371/journal.pone.0120601.

23. Grandes-Blanco, A.I.; Díaz-Godínez, G.; Téllez-Téllez, M.; Delgado-Macuil, R.J.; Rojas-López, M.; Bibbins-Martínez, M.D. Ligninolytic activity patterns of pleurotus ostreatus obtained by submerged fermentation in presence of 2,6-dimethoxyphenol and remazol brilliant blue R dye. Prep. Biochem. Biotechnol. 2013, 43, 468-480, doi:10.1080/10826068.2012.746233.

24. Díaz, R.; Téllez-Téllez, M.; Sánchez, C.; Bibbins-Martínez, M.D.; Díaz-Godínez, G.; Soriano-Santos, J. Influence of initial pH of the growing medium on the activity, production and genes expression profiles of laccase of Pleurotus ostreatus in submerged fermentations. Electron. J. Biotechnol. 2013, 16, doi:10.2225/vol16-issue4-fulltext-6.

25. Téllez-Téllez, M.; Díaz-Godínez, G.; Aguilar, M.B.; Sánchez, C.; Fernández, F.J. Description of a laccase gene from Pleurotus ostreatus expressed under submerged fermentation conditions. BioResources 2012, 7, 2038-2050.

26. Téllez-Téllez, M.; Fernández, F.J.; Montiel-González, A.M.; Sánchez, C.; Díaz-Godínez, G. Growth and laccase production by Pleurotus ostreatus in submerged and solid-state fermentation. Appl. Microbiol. Biotechnol. 2008, 81, 675-679, doi:10.1007/s00253008-1628-6.

27. Tlecuitl-Beristain, S.; Sánchez, C.; Loera, O.; Robson, G.D.; Díaz-Godínez, G. Laccases of Pleurotus ostreatus observed at different phases of its growth in submerged fermentation: production of a novel laccase isoform. Mycol. Res. 2008, 112, 10801084, doi:10.1016/j.mycres.2008.03.001.

28. Lettera, V.; Del Vecchio, C.; Piscitelli, A.; Sannia, G. Low impact strategies to improve ligninolytic enzyme production in filamentous fungi: The case of laccase in Pleurotus ostreatus. Comptes Rendus - Biol. 2011, 334, 781-788, doi:10.1016/j.crvi.2011.06.001.

29. Tinoco-Valencia, R.; Gómez-Cruz, C.; Galindo, E.; Serrano-Carreón, L. Toward an understanding of the effects of agitation and aeration on growth and laccases production by Pleurotus ostreatus. J. Biotechnol. 2014, 177, 67-73, doi:10.1016/j.jbiotec.2014.02.013. 
30. Parenti, A.; Muguerza, E.; Redin Iroz, A.; Omarini, A.; Conde, E.; Alfaro, M.; Castanera, R.; Santoyo, F.; Ramírez, L.; Pisab arro, A.G. Induction of laccase activity in the white rot fungus Pleurotus ostreatus using water polluted with wheat straw extracts. Bioresour. Technol. 2013, 133, 142-149, doi:10.1016/j.biortech.2013.01.072.

31. Mikiashvili, N.; Wasser, S.P.; Nevo, E.; Elisashvili, V. Effects of carbon and nitrogen sources on Pleurotus ostreatus ligninolytic enzyme activity. World J. Microbiol. Biotechnol. 2006, 22, 999-1002, doi:10.1007/s11274-006-9132-6.

32. Tinoco, R.; Acevedo, A.; Galindo, E.; Serrano-Carreón, L. Increasing Pleurotus ostreatus laccase production by culture medium optimization and copper/lignin synergistic induction. J. Ind. Microbiol. Biotechnol. 2011, 38, 531-540, doi:10.1007/s10295-010-07973.

33. Stajić, M.; Persky, L.; Friesem, D.; Hadar, Y.; Wasser, S.P.; Nevo, E.; Vukojević, J. Effect of different carbon and nitrogen sources on laccase and peroxidases production by selected Pleurotus species. Enzyme Microb. Technol. 2006, 38, 65-73, doi:10.1016/j.enzmictec.2005.03.026.

34. Efeyan, A.; Comb, W.C.; Sabatini, D.M. Nutrient-sensing mechanisms and pathways. Nature 2015, 517, 302-310, doi:10.1038/nature14190.

35. Brown, N.A.; Ries, L.N.; Goldman, G.H. How nutritional status signalling coordinates metabolism and lignocellulolytic enzyme secretion. Fungal Genet. Biol. 2014, 72, 48-63.

36. Adnan, M.; Zheng, W.; Islam, W.; Arif, M.; Abubakar, YS; Wang, Z.; Lu, G. Carbon catabolite repression in filamentous Fungi. Int. J. Mol. Sci. 2018, 19, 1-24, doi:10.3390/ijms19010048.

37. Huberman, L.B.; Liu, J.; Qin, L.; Glass, N.L. Regulation of the lignocellulolytic response in filamentous fungi. Fungal Biol. Rev. 2016, 30, 101-111, doi:10.1016/j.fbr.2016.06.001.

38. de Assis, L.J.; Silva, L.P.; Bayram, O.; Dowling, P.; Kniemeyer, O.; Krüger, T.; Brakhage, A.A.; Chen, Y.; Dong, L.; Tan, K.; et al. Carbon catabolite repression in filamentous fungi is regulated by phosphorylation of the transcription factor crea. MBio 2021, 12, 1-21, doi:10.1128/mBio.03146-20.

39. Davis, M.A.; Wong, K.H. Nitrogen Metabolism in Filamentous Fungi. Cell. Mol. Biol. Filamentous Fungi 2010, 325-338, doi:10.1128/9781555816636.ch23.

40. Tudzynski, B. Nitrogen regulation of fungal secondary metabolism in fungi. Front. Microbiol. 2014, 5, 1-15, doi:10.3389/fmicb.2014.00656.

41. Han, X.; Qiu, M.; Wang, B.; Yin, W.; Nie, X.; Qin, Q.; Ren, S.; Yang, K.; Zhang, F.; Zhuang, Z.; et al. Functional Analysis of the Nitrogen Metabolite Repression Regulator Gene nmrA in Aspergillus flavus. 2016, 7, 1-12, doi:10.3389/fmicb.2016.01794.

42. Todd, R.B.; Fraser, J.A.; Wong, K.H.; Davis, M.A.; Hynes, M.J. Nuclear Accumulation of the GATA Factor AreA in Response to Complete Nitrogen Starvation by Regulation of Nuclear Export. 2005, 4, 1646-1653, doi:10.1128/EC.4.10.1646.

43. Wong, K.H.; Hynes, M.J.; Todd, R.B.; Davis, M.A. Transcriptional control of nmrA by the bZIP transcription factor MeaB reveals a new level of nitrogen regulation in Aspergillus nidulans. 2007, 66, 534-551, doi:10.1111/j.1365-2958.2007.05940.x.

44. Fernandez, J.; Wright, J.D.; Hartline, D.; Quispe, C.F.; Madayiputhiya, N.; Wilson, R.A. Principles of Carbon Catabolite Repression in the Rice Blast Fungus: Tps1 , Nmr1-3, and a MATE - Family Pump Regulate Glucose Metabolism during Infection. PLos Genet. 2012, 8, doi:10.1371/journal.pgen.1002673.

45. Harris, E.D. Cellular Copper Transport and Metabolism. Annu. Rev. Nutr. 2000, 20, 291-310.

46. Kardos, J.; Héja, L.; Simon, Á.; Jablonkai, I.; Kovács, R.; Jemnitz, K. Copper signalling: causes and consequences. Cell Commun. Signal. 2018, 16, 1-22, doi:10.1186/s12964-018-0292-4.

47. Petris, MJ The SLC31 ( Ctr ) copper transporter family. 2004, 752-755, doi:10.1007/s00424-003-1092-1.

48. Smith, A.D.; Logeman, B.L.; Thiele, D.J. Copper Acquisition and Utilization in Fungi. Annu. Rev. Microbiol. 2017, 71, 597-623.

49. Choi, M.; Davidson, V.L. Cupredoxins - A study of how proteins may evolve to use metals for bioenergetic processes. Metallomics 2011, 3, 140-151, doi:10.1039/c0mt00061b.

50. Lu, Y. Electron Transfer: Cupredoxins. Compr. Coord. Chem. II 2003, 8, 91-122, doi:10.1016/B0-08-043748-6/08172-X.

51. Baldrian, P. Fungal laccases-occurrence and properties. FEMS Microbiol. Rev. 2006, 30, 215-242, doi:10.1111/j.15744976.2005.00010.x.

52. Bassanini, I.; Ferrandi, E.E.; Riva, S.; Monti, D. Biocatalysis with laccases: An updated overview. Catalysts 2021, 11, 1-30, doi:10.3390/catal11010026.

53. Galhaup, C.; Wagner, H.; Hinterstoisser, B.; Haltrich, D. Increased production of laccase by the wood-degrading basidiomycete Trametes pubescens. Enzyme Microb. Technol. 2002, 30, 529-536, doi:10.1016/S0141-0229(01)00522-1.

54. GL., M. Use of DinitrosaIicylic Acid Reagent for Determination of Reducing Sugar. Anal. Chem. 1959, 31, 426-428.

55. Bradford, M.M. A Rapid and Sensitive Method for the Quantitation Microgram Quantities of Protein Utilizing the Principle of Protein-Dye Binding. 1976, 254, 248-254.

56. Lettera, V.; Piscitelli, A.; Leo, G.; Birolo, L.; Pezzella, C.; Sannia, G. Identification of a new member of Pleurotus ostreatus laccase family from mature fruiting body. Fungal Biol. 2010, 114, 724-730, doi:10.1016/j.funbio.2010.06.004.

57. Castanera, R.; López-Varas, L.; Pisabarro, A.G.; Ramíre, L. Validation of reference genes for transcriptional analyses in Pleurotus ostreatus by using reverse transcription-quantitative PCR. Appl. Environ. Microbiol. 2015, 81, 4120-4129, doi:10.1128/AEM.0040215.

58. Castanera, R.; Omarini, A.; Santoyo, F.; Pérez, G.; Pisabarro, A.G.; Ramírez, L. Non-Additive Transcriptional Profiles Underlie Dikaryotic Superiority in Pleurotus ostreatus Laccase Activity. PLoS One 2013, 8, doi:10.1371/journal.pone.0073282.

59. Dobin, A.; Davis, C.A.; Schlesinger, F.; Drenkow, J.; Zaleski, C.; Jha, S.; Batut, P.; Chaisson, M.; Gingeras, T.R. STAR: ultrafast universal RNA-seq aligner. Bioinformatics 2013, 29, 15-21, doi:10.1093/bioinformatics/bts635. 
60. Larraya, L.M.; Perez, G.; Penas, MM; Baars, J.J.P.; Mikosch, T.S.P.; Pisabarro, A.G.; Ramirez, L. Molecular Karyotype of the White Rot Fungus Pleurotus ostreatus. Appl. Envir. Microbiol. 1999, 65, 3413-3417.

61. Riley, R.; Salamov, A.A.; Brown, D.W.; Nagy, L.G.; Floudas, D.; Held, BW; Levasseur, A.; Lombard, V.; Morin, E.; Otillar, R.; et al. Extensive sampling of basidiomycete genomes demonstrates inadequacy of the white-rot/brown-rot paradigm for wood decay fungi. Proc. Natl. Acad. Sci. U. S. A. 2014, 111, 9923-8, doi:10.1073/pnas.1400592111.

62. Grigoriev, I. V.; Nikitin, R.; Haridas, S.; Kuo, A.; Ohm, R.; Otillar, R.; Riley, R.; Salamov, A.; Zhao, X.; Korzeniewski, F.; et al. MycoCosm portal: Gearing up for 1000 fungal genomes. Nucleic Acids Res. 2014, 42, 699-704, doi:10.1093/nar/gkt1183.

63. Zhang, Z.; Schwartz, S.; Wagner, L.; Miller, W. A greedy algorithm for aligning DNA sequences. J. Comput. Biol. 2000, 7, 203214.

64. Morgulis, A.; Coulouris, G.; Raytselis, Y.; Madden, TL; Agarwala, R.; Schäffer, A.A. Database indexing for production MegaBLAST searches. Bioinforma. Orig. Pap. 2008, 24, 1757-1764, doi:10.1093/bioinformatics/btn322.

65. Kachlishvili, E.; Penninckx, M.J.; Tsiklauri, N.; Elisashvili, V. Effect of nitrogen source on lignocellulolytic enzyme production by white-rot basidiomycetes under solid-state cultivation. World J. Microbiol. Biotechnol. 2006, 22, 391-397, doi:10.1007/s11274005-9046-8.

66. Stajić, M.; Persky, L.; Friesem, D.; Hadar, Y.; Wasser, S.P.; Nevo, E.; Vukojević, J. Effect of different carbon and nitrogen sources on laccase and peroxidases production by selected Pleurotus species. Enzyme Microb. Technol. 2006, 38, 65-73, doi:10.1016/j.enzmictec.2005.03.026.

67. D’Agostini, É.C.; Mantovani, T.R.D.; Valle, J.S. Do; Paccola-Meirelles, L.D.; Colauto, N.B.; Linde, G.A. Low carbon/nitrogen ratio increases laccase production from basidiomycetes in solid substrate cultivation. Sci. Agric. 2011, 68, 295-300, doi:10.1590/S0103-90162011000300004.

68. Zhu, C.; Bao, G.; Huang, S. Optimization of laccase production in the white-rot fungus Pleurotus ostreatus (ACCC 52857) induced through yeast extract and copper. Biotechnol. Biotechnol. Equip. 2016, 30, 270-276, doi:10.1080/13102818.2015.1135081.

69. Karp, S.G.; Faraco, V.; Amore, A.; Alberto, L.; Letti, J.; Soccol, V.T.; Soccol, C.R. Statistical Optimization of Laccase Production and Delignification of Sugarcane Bagasse by Pleurotus ostreatus in Solid-State Fermentation. 2015, 2015.

70. Barelle, C.J.; Bohula, E.A.; Kron, S.J.; Wessels, D.; Soll, D.R.; Schäfer, A.; Brown, A.J.P.; Gow, N.A.R. Asynchronous cell cycle and asymmetric vacuolar inheritance in true hyphae of Candida albicans. Eukaryot. Cell 2003, 2, 398-410, doi:10.1128/EC.2.3.398410.2003.

71. Periasamy, R.; Palvannan, T. Optimization of laccase production by Pleurotus ostreatus IMI 395545 using the Taguchi DOE methodology. J. Basic Microbiol. 2010, 50, 548-556, doi:10.1002/jobm.201000095.

72. Yang, J.; Wang, G.; Ng, TB; Lin, J.; Ye, X. Laccase production and differential transcription of laccase genes in cerrena sp. in response to metal ions, aromatic compounds, and nutrients. Front. Microbiol. 2016, 6, 1-11, doi:10.3389/fmicb.2015.01558.

73. Hazuchová, M.; Chmelová, D.; Ondrejovič, M. The optimization of propagation medium for the increase of laccase production by the white-rot fungus Pleurotus ostreatus. Nov. Biotechnol. Chim. 2017, 16, 113-123, doi:10.1515/nbec-2017-0016.

74. Baldrian, P.; Gabriel, J. Copper and cadmium increase laccase activity in Pleurotus ostreatus. FEMS Microbiol. Lett. 2002, 206, 69-74, doi:10.1016/S0378-1097(01)00519-5.

75. Kannaiyan, R.; Kostenko, V.; Martinuzzi, R.J. Nutrient media optimization for simultaneous enhancement of the laccase and peroxidases production by coculture of Dichomitus squalens and Ceriporiopsis subvermispora. 173-185, doi:10.1002/bab.1263.

76. Kannaiyan, R.; Mahinpey, N.; Mani, T.; Martinuzzi, R.J.; Kostenko, V. Enhancement of Dichomitus squalens tolerance to copper and copper-associated laccase activity by carbon and nitrogen sources. 2012, 67, 140-147.

77. Chenthamarakshan, A.; Parambayil, N.; Miziriya, N.; Soumya, P.S.; Lakshmi, M.S.K. Optimization of laccase production from Marasmiellus palmivorus LA1 by Taguchi method of design of experiments. BMC Biotechnol. 2017, 17, 1-10, doi:10.1186/s12896017-0333-x.

78. HM, B.; HP, J.; RZ, S. Statistical optimization for enhanced production of extracellular laccase from Aspergillus sp . HB _ RZ4 isolated from bark scrapping. Environ. Sustain. 2018, 1, 159-166.

79. Palmieri, G.; Giardina, P.; Bianco, C.; Fontanella, B.; Sannia, G. Copper induction of laccase isoenzymes in the ligninolytic fungus Pleurotus ostreatus. Appl. Environ. Microbiol. 2000, 66, 920-924, doi:10.1128/AEM.66.3.920-924.2000.

80. Palmieri, G.; Cennamo, G.; Faraco, V.; Amoresano, A.; Sannia, G.; Giardina, P. Atypical laccase isoenzymes from copper supplemented Pleurotus ostreatus cultures \&. 2003, 33, 220-230, doi:10.1016/S0141-0229(03)00117-0.

81. Peñas, M.M.; Azparren, G.; Domínguez, Á.; Sommer, H.; Ramírez, L.; Pisabarro, A.G. Identification and functional characterisation of ctr1, a Pleurotus ostreatus gene coding for a copper transporter. Mol. Genet. Genomics 2005, 274, 402-409, doi:10.1007/s00438-005-0033-4. 